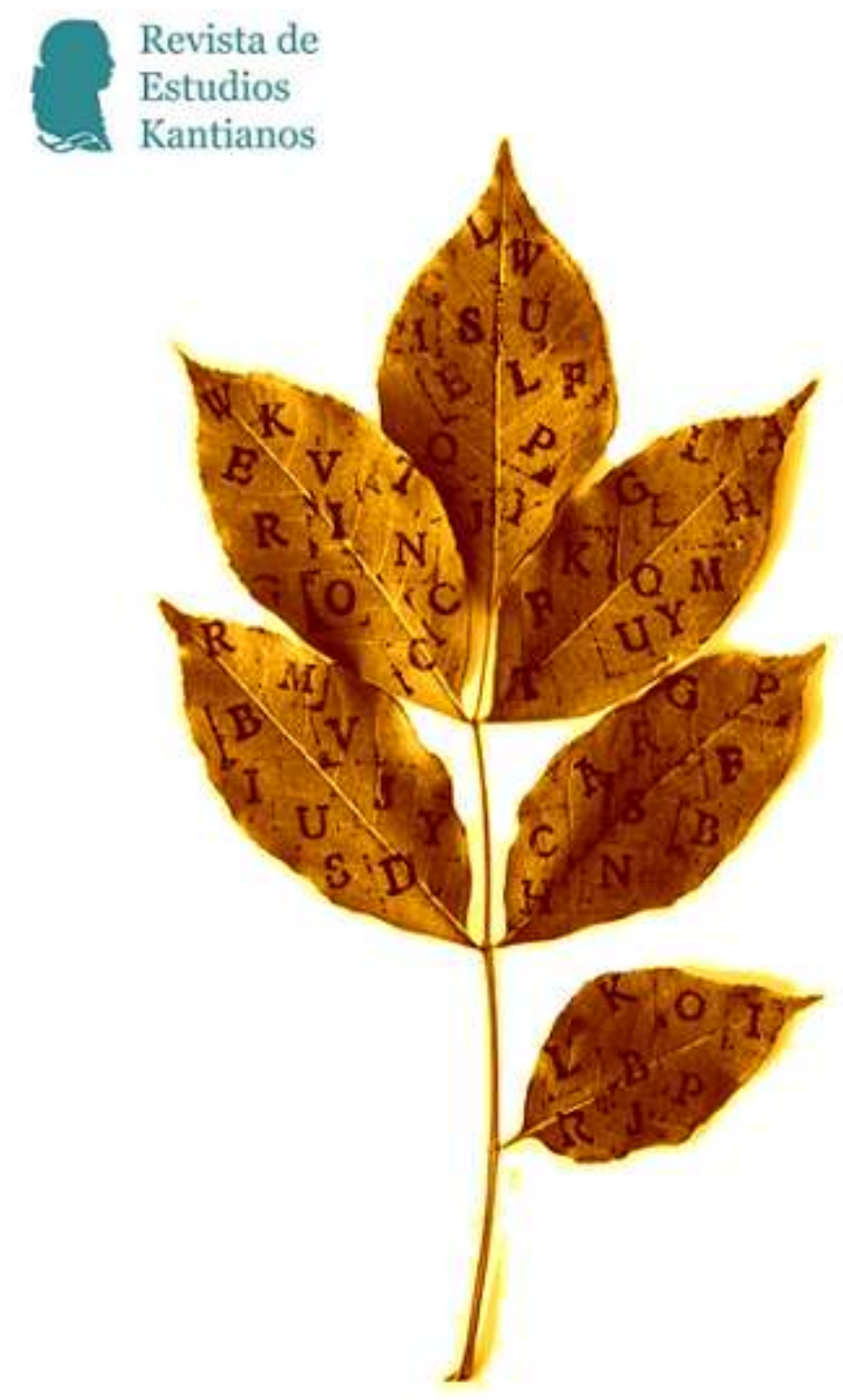




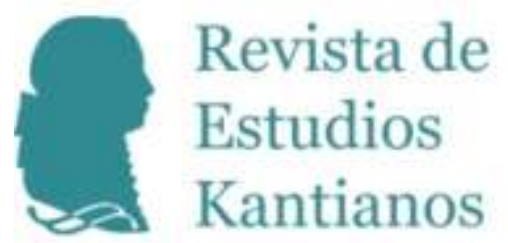




\section{Revista de Estudios Kantianos}

Publicación internacional de la Sociedad de Estudios Kantianos en Lengua Española Internationale Zeitschrift der Gesellschaft für Kant-Studien in Spanischer Sprache International Journal of the Society of Kantian Studies in the Spanish Language

\section{Dirección}

Pedro Jesús Teruel, Universitat de València

pedro.teruel@uv.es

Hernán Pringe, CONICET-Universidad de Buenos Aires/

Universidad Diego Portales, Santiago de Chile

hpringe@gmail.com

\section{Secretario de edición}

Fernando Moledo, Universidad de Buenos Aires - CONICET

fernandomoledo@gmail.com

\section{Secretaria de calidad}

Marcela García, Instituto de Investigaciones Filosóficas, UNAM

garciar.marcela@gmail.com

\section{Editores científicos}

Jacinto Rivera de Rosales, UNED, Madrid

Claudia Jáuregui, Universidad de Buenos Aires

Vicente Durán, Pontificia Universidad Javeriana, Bogotá

Julio del Valle, Pontificia Universidad Católica del Perú, Lima

Jesús Conill, Universitat de València

Gustavo Leyva, Universidad Autónoma de México, México D. F.

María Xesús Vázquez Lobeiras, Universidade de Santiago de Compostela

Wilson Herrera, Universidad del Rosario, Bogotá

Pablo Oyarzun, Universidad de Chile, Santiago de Chile

Paula Órdenes Azúa, Universität Heidelberg 


\section{Comité científico}

Juan Arana, Universidad de Sevilla

Reinhardt Brandt, Philipps-Universität Marburg

Mario Caimi, Universidad de Buenos Aires

Monique Castillo, Université de Paris-Est

Adela Cortina, Universitat de València

Bernd Dörflinger, Universität Trier

Norbert Fischer, Universität Eichstätt-Ingolstadt

Miguel Giusti, Pontificia Universidad Católica del Perú

Dulce María Granja, Universidad Nacional Autónoma de México

Christian Hamm, Universidad Federal de Santa María, Brasil

Dietmar Heidemann, Université du Luxembourg

Otfried Höffe, Universität Tübingen

Claudio La Rocca, Università degli Studi di Genova

Juan Manuel Navarro Cordón, Universidad Complutense, Madrid

Carlos Pereda, Universidad Nacional Autónoma de México

Gustavo Pereira, Universidad de la República, Uruguay

Ubirajara Rancan de Azevedo, Universidade Estadual Paulista, Brasil

Margit Ruffing, Johannes Gutenberg-Universität Mainz

Gustavo Sarmiento, Universidad Simón Bolívar, Venezuela

Sergio Sevilla, Universitat de València

Roberto Torretti, Universidad Diego Portales, Santiago de Chile

Violetta Waibel, Universität Wien

Howard Williams, University of Aberystwyth

Allen W. Wood, Indiana University

Diseño, revisión de estilo y maqueta

Josefa Ros Velasco, Universidad Complutense de Madrid

\section{Entidades colaboradoras}

Sociedad de Estudios Kantianos en Lengua Española (SEKLE)

Departament de Filosofia de la Universitat de València 


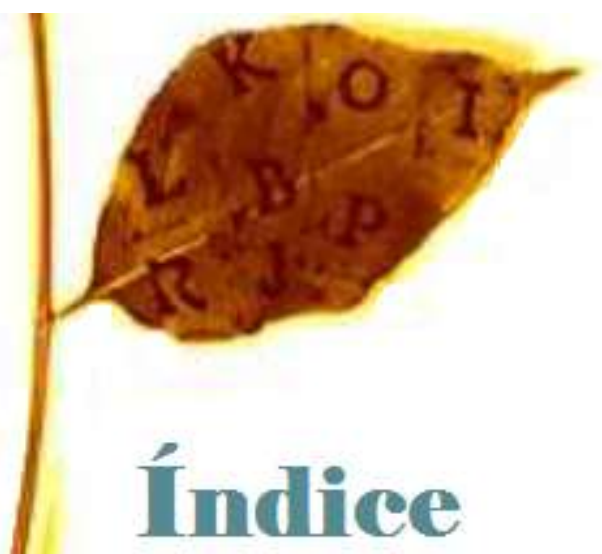

\section{Artículos}

113 ¿"El yo propiamente tal” (I. Kant) o "el originario ser sí mismo” (D. Heinrich)? Sobre algunas características del concepto kantiano de autoconciencia

Heiner Klemme

DOI 10.7203/REK.2.2.9068

126 La noción kantiana de verdad transcendental

Stéfano Straulino Torre

DOI 10.7203/REK.2.2.8809

146 Una travesía kantiana a través del Escila constructivista y el Caribdis realista. Apuntes para un abordaje kantiano-constitutivista de las fuentes de la normatividad

Martín Fleitas González

DOI 10.7203/REK.2.2.8810

174 El malestar kantiano. Filosofía y ciencia al encuentro con la naturaleza Juan Felipe Guevara

DOI 10.7203/REK.2.2.8812

191 ¿Puede haber una fundamentación kantiana de los derechos humanos? Algunas consideraciones críticas

Nuria Sánchez Madrid

DOI 10.7203/REK.2.2.8871

\section{Semblanza}

208 El pensamiento filosófico de Ernesto Mayz Vallenilla

Gustavo Sarmiento

DOI 10.7203/REK.2.2.9021 


\section{Reseñas}

217 Claudia Jáuregi, Fernando Moledo, Hernán Pringe y Marcos Thisted (eds.) Crítica y Metafísica. Homenaje a Mario Caimi. Studien und Materialen zur Geschichten der Philosophie. Hildesheim, Olms, 2015, 460 pp. ISBN: 978-3-487-15237-0.

Alba Jiménez Rodríguez.

DOI 10.7203/REK.2.2. 8814

227 Fernando Moledo: Los años silenciosos de Kant: Aspectos de la génesis de la Deducción Trascendental en la década de 1770. Seguido de la traducción del Legado de Duisburg (ca. 1775). Buenos Aires, Prometeo, 2014, 192 pp. ISBN: 978-987-574-667-1.

Pablo Moscón DOI 10.7203/REK.2.2. 8830

231 Salvi Turró: Filosofia i Modernitat. La reconstrucció de l'ordre del món. Barcelona, Edicions Universitat de Barcelona, 2016, 228 pp. ISBN: 978-84-475-3966-6.

Pedro Jesús Teruel

DOI 10.7203/REK.2.2. 8887

233 Gabriel Rivero: Zur Bedeutung des Begriffs Ontologie bei Kant. Berlín, Boston, Walter de Gruyter, 2014, 247 pp. ISBN: 978-3-11-034180-5.

Luciana Martínez

DOI 10.7203/REK.2.2.8881

Informe

237 Informe sobre el III Congreso de la Sociedad de Estudios Kantianos en Lengua Española (SEKLE)

Luciana Martínez

DOI 10.7203/REK.2.2.9011

\section{Convocatoria}

242 La recepción de Kant en México

Dulce María Granja Castro; Gustavo Leyva Martínez

Eventos y normas para la publicación

244 Noticias y normas para autores 


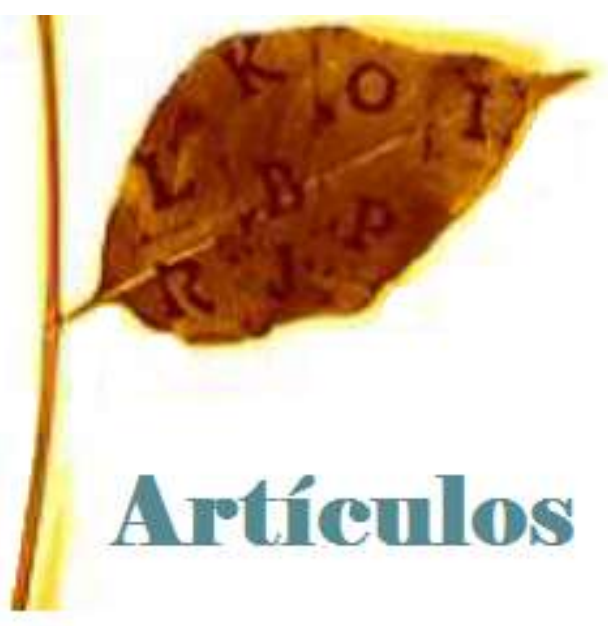




\title{
La noción kantiana de verdad trascendental
}

\author{
STÉFANO STRAULINO TORRE ${ }^{1}$
}

\begin{abstract}
Resumen
El objetivo de este trabajo es dilucidar la noción de "verdad trascendental" y mostrar su lugar en el sistema kantiano. Se defenderá que la verdad trascendental consiste, en línea con la definición tradicional de verdad, en un sentido de correspondencia entre conocimiento y objeto, que la lógica trascendental establece criterios de verdad trascendental, y que es esta noción de verdad la que permite establecer la verdad del conocimiento a priori y delimitar el territorio de la verdad empírica.
\end{abstract}

Palabras clave: criterios de verdad, experiencia posible, objetividad, verdad trascendental

\section{Kant's notion of transcendental truth}

\begin{abstract}
The aim of this work is to elucidate the notion of "transcendental truth" and to show its role in the Kantian system. I will argue that this notion is in line with the traditional definition of truth, i.e., that it consists in the correspondence between knowledge and object. I will also argue that criteria of transcendental truth are provided by transcendental logic, and that it is this notion of truth what makes it possible to establish the truth of a priori knowledge and delimitate the field of empirical truth.
\end{abstract}

Keywords: Objectivity, possible experience, transcendental truth, truth criteria.

Introducción $^{2}$

Como reconocen diversos estudiosos, Kant no es muy prolijo al hablar sobre la verdad (e.g. Cicovacki 1995: 199-200; Palacios 2013: 13; Vanzo 2010: 147-148). Las ocasiones en que aborda directamente este tema son contadas: además de un pasaje en la Crítica de la razón pura (KrV A57-59/B82-84) ${ }^{3}$, la mayor parte de los acercamientos al tema se encuentran en ciertos lugares de sus lecciones de lógica, donde la cuestión se tocaba como parte del temario fijado por los manuales de la época. Esta parquedad resulta especialmente notable si se tiene en cuenta que Kant centra la novedad de su pensamiento -como anuncia con la idea de la revolución copernicana en el prólogo a la segunda edición de la Crítica ( $\mathrm{KrV}$ Bxvi)- precisamente en la inversión de la relación que se tiene, tradicionalmente, por la definición misma de la verdad: la correspondencia del conocimiento con su objeto $^{4}$.

A pesar de la falta de una exposición sistemática sobre la noción de verdad, Kant hace uso de distintos sentidos del mismo término, por ejemplo: verdad formal, verdad material, verdad trascendental, verdad empírica; además de introducir diferentes matices: definición real o nominal de verdad, criterios internos, externos, universales, suficientes, materiales o formales de verdad. Entre todas estas nociones destaca particularmente -para la correcta comprensión de la novedad del planteamiento kantiano y, particularmente, de su doctrina de la objetividad- la de 'verdad

${ }^{1}$ Universidad Panamericana. Campus México. Departamento de Humanidades.

${ }^{2}$ Deseo expresar aquí mi gratitud a los profesores Alejandro Llano y José María Torralba por sus observaciones y su ayuda en la elaboración de este trabajo.

Nota del editor: artículo ganador del $1^{\mathrm{er}}$ premio SEKLE

${ }^{3}$ Como es habitual, se cita Crítica de la razón pura indicando A para la primera edición y B para la segunda. El resto del corpus kantiano se cita indicando la abreviación de la Kant-Forschungsstelle y el volumen y páginas en la edición de la Academia.

${ }^{4}$ Definición que, por cierto, Kant mismo "concede y presupone" (KrV A58, B82). De esto hablaremos más adelante. 
trascendental', a la que, sin embargo, apenas dedica atención explícita. En efecto, esta expresión, 'verdad trascendental' (transscendentale Wahrheit), aparece expresamente sólo dos veces en la Crítica de la razón pura (KrV A146/B185 y A222/B269) ${ }^{5}$ y en ningún otro lugar de la obra publicada de Kant ${ }^{6}$. Aunque este término no es acuñado por Kant, sí es, en cambio, dotado de un nuevo sentido en el marco de su doctrina crítica ${ }^{7}$.

En este trabajo pretendo esclarecer el sentido de esta noción. Para ello, en la primera parte se analizan los pasajes de la Crítica de la razón pura en los que aparece explícitamente el término 'verdad trascendental'. Tras esto, en la segunda parte se expone el carácter de dicha noción como criterio de verdad, particularmente en su relación con el conocimiento a priori. Finalmente, en la última sección, se despliega su alcance sistemático, exponiendo su relación con los fundamentos del planteamiento crítico y con la posibilidad del conocimiento en general.

1. Verdad, realidad objetiva y experiencia posible

Para comprender cabalmente el sentido del término 'verdad trascendental', resulta pertinente hacer antes una breve exposición de lo que Kant entiende por 'verdad' en su sentido más general. En un famoso pasaje de la "Introducción a la lógica general", Kant señala que "concede y presupone" la definición tradicional de verdad, esto es, la "correspondencia del conocimiento con su objeto" (KrV A58/B82). A pesar de ello, existe un debate largo y continuado en torno al grado de compromiso que la aceptación de tal definición implica respecto de una teoría de la verdad como correspondencia, o si acaso esta definición no tiene mayor relevancia ${ }^{8}$. En buena medida, este debate es alimentado por la caracterización que Kant hace de esta definición como una definición nominal ${ }^{9}$.

Así pues, ¿qué implica que 'la concordancia del conocimiento con su objeto' sea la definición nominal de la verdad? Que Kant admite esta definición se da por supuesto, no sólo por el pasaje en el que dice que tal definición "se concede y presupone", sino por las múltiples referencias que hace a esta noción como definición de verdad (por ejemplo: KrV A157/B196-197, A191/B236, A237/B296, A642/B670, Prol 4: 279, Log 9: 50, V-Lo/Wiener 24: 822, V-Met/Volckmann 28: 415, VMet/Schön 28: 497) ${ }^{10}$. ¿Qué indica, entonces, su carácter nominal? En términos generales, una definición nominal se caracteriza, en oposición a una definición real, por no ofrecer la totalidad de la esencia de lo definido. Las definiciones reales muestran la posibilidad del objeto a partir de notas internas; son esenciales y contienen el concepto de la esencia (real) de la cosa (Log 9: 143; V-

\footnotetext{
${ }^{5}$ Sin embargo, de ser correcta la interpretación que se llevará a cabo en este trabajo, hay otros pasajes en que es necesario leer 'verdad' en este sentido, por ejemplo: KrV A124-125, A128, A157-158/B196-197, A237/B296.

${ }^{6}$ Aparece, en cambio, en algunas reflexiones y en algunas lecciones de metafísica (Refl 3765 17: 287, Refl 4806 18: 734, V Met/Herder 28: 17, V-Met/Volckmann 28: 415, V-Met/Schön 28: 496-497, V-Met-L2/Pölitz 28: 556, V-Met/Dohna 28: 632, VMet-K2/Heinze 28: 714, V-Met-K3E/Arnoldt 29: 989-990). Sin embargo, en estos pasajes es discutida más bien la acepción que le daban los manuales, y no el sentido en que Kant la toma en su doctrina crítica (ver siguiente nota).

${ }^{7}$ Kant toma el término 'verdad trascendental' de la interpretación wolffiana de la doctrina escolástica de los trascendentales, de la que más tarde se distancia y a la que critica, como es patente en el §12 de la Crítica (KrV B113-116; ver también V-Met/Schön 28 495-497). En aquella interpretación, la 'verdad trascendental' es tomada como el orden interno de las cosas (Wolff 1736: \$495502; cf. Baumgarten 1757: §89-90; Meier 1765: §90-91). Sobre la influencia de los predecesores de Kant -especialmente Wolff y Baumgarten- en la acuñación de dicho término, véase: Sgarbi 2011: 97-117; Rosales 2000: 44-46; Pieper 1974: 116-121; Albrech 2006: 243-248.

${ }^{8}$ En líneas generales, se pueden identificar tres posturas al respecto. En primer lugar, los intérpretes que sostienen que la definición que Kant ofrece le compromete con una teoría de la verdad como correspondencia. A este grupo pertenecen, entre otros, Heidegger (1979: 215), Hiltscher (1988), Höffe (2010: 185), Neiman (1994: 6-7) y Underwood (2003). En segundo lugar, quienes indican que el carácter nominal de la definición es un modo de trivializarla y, en última instancia, de rechazarla. Aquí destacan: Prauss (1969: 166-82), Walker (1983: 160), Esterhuyse (1972: 284-286) y Hofmeister (1972: 316-317). Y por último, quienes afirman que tal definición ofrece una explicación genuina del significado de 'verdad', pero no compromete con una teoría concreta, puesto que no da cuenta de todas las características de la misma, no implica una definición real ni un criterio de verdad ni, tampoco, un compromiso metafísico o epistemológico. En este tercer grupo podemos encontrar a Capozzi (2002: 503), Vanzo (2010: 166) Cicovacki (1995: 199), Nenon (1986: 19 ss) y Hanna (2000: 233-240).

${ }^{9}$ Son contados los intérpretes que hacen un análisis pormenorizado de la noción de 'definición nominal' para dilucidar el sentido de la noción de verdad aceptada por Kant. Entre ellos destacan especialmente Nenon (1986: 19-38) y Vanzo (2010). Las consideraciones que se hacen a continuación deben mucho a estos dos trabajos.

${ }^{10}$ Una notable excepción al acuerdo general de que Kant acepta esta definición (aunque sea sólo en su carácter nominal) es Gerold Prauss. Según él, cuando Kant dice que "se concede y se presupone aquí la definición nominal de verdad" (KrV A58/B82), con la palabra 'aquí' no se refiere a su propia doctrina. En realidad Kant se referiría a la situación en la que se le pregunta al lógico por la verdad. La situación a la que el lógico se ve abocado por aceptar tal definición (caer en un sofisma o aceptar la vanidad de su arte) llevaría a Kant -según Prauss-, a rechazarla (Prauss 1969: 167). No cabe hacer un análisis exhaustivo de esta interpretación. Basta de momento señalar que este argumento sólo es plausible en el marco del pasaje analizado, donde Kant hace referencia a los lógicos. Pero Kant ofrece la misma noción de verdad, sin problematizarla, en otros varios lugares (véase el paréntesis antes de esta nota). En contra de la interpretación de Prauss: Wagner (1977: 71-76), Nenon (1986: 40n).
} 
Lo/Wiener 24: 919; V-Lo/Blomberg 24: 268). En este sentido, ofrecen la totalidad de las características (o notas) de aquello que definen y, con ello, exhiben además su posibilidad real (KrV A241-242 nota). Las definiciones nominales, en cambio, tienen como fin fijar el uso del nombre de un concepto: "la palabra, con las pocas notas ligadas a ella, es sólo una denominación de la cosa, y no un concepto de ella; y por tanto, la presunta definición no es otra cosa que una determinación de la palabra" (KrV A728/B756; cf. Log 9: 143; V-Lo/Wiener 24: 919; V-Lo/Blomberg 24: 268). Por ello, no necesitan ofrecer la totalidad de notas del concepto definido, sino solo aquellas que sirvan para distinguirlo de otros: "el término 'definición nominal' [indica] un cierto testimonio de la denominación de la cosa, para hacer claro el nombre de la cosa, pero no para comprender mejor la cosa misma. No comprende la esencia de la cosa en sí, sino solo la comparación de algunas marcas de diferenciación con otras" (V-Lo/Wiener 24: 919; cf. KrV A241-242 nota; Br 11: 36-37; ver: Capozzi 2002: 499-503; Cabrera 1995: 130-133). Así pues, las definiciones nominales no expresan la totalidad del concepto de un objeto, pero sí ofrecen una serie de notas que pertenecen realmente al objeto (Vanzo 2010: 156-159), y que permiten distinguirlo de otros conceptos.

Que la definición tradicional de verdad no sea una definición real implica que la noción de "correspondencia del conocimiento con su objeto" (Capozzi 2002: 503) no agota el concepto de verdad y, por ende, no constituye ni implica una teoría completa de la verdad. En contraste con los conceptos creados sintética y arbitrariamente mediante definiciones reales (por ejemplo, en el caso de las matemáticas), que por sí mismas expresan la posibilidad de su objeto, los conceptos presuntamente 'dados' (sean empíricos o metafísicos) implican la brecha entre sus cualidades objetivas y nuestro conocimiento subjetivo; por lo que, en primer lugar, puede ser que las notas especificadas para la definición nominal de una palabra determinada no sean suficientes para describir a la cosa misma y, en segundo lugar, también puede suceder que la palabra definida no se refiera, o no se pueda referir, a ninguna cosa real dada (Nenon 1986: 31).

No es posible, pues, como pretenden algunos intérpretes, deducir sólo de la aceptación de esta definición que Kant abraza una teoría de la verdad como correspondencia. Sin embargo, calificar esta definición como 'nominal' tampoco es un modo de restarle toda importancia. Si se acepta que esta es una definición nominal válida de verdad, entonces se acepta que la concordancia es una nota de la verdad. En palabras de Capozzi, "decir 'verdad' es decir 'adaequatio intellectus et rei' y si cambiase en cualquier modo el definiens se debe admitir estar hablando de algún otro concepto y, en sentido estricto, este último debe ser designado por otro nombre" (Capozzi 2002: 503; cf. Cicovacki 1995: 199-200, 2002: 16; Vanzo 2010: 166) ${ }^{11}$.

La definición nominal de 'verdad' sirve, en efecto, para tener un concepto diferenciado que pueda ser usado de manera suficientemente válida. No explica totalmente qué es la verdad y mucho menos da cuenta de su posibilidad, pero ofrece notas características que nos permiten distinguir este concepto de otros; permite referirnos a él correctamente al dar cuenta del uso ordinario que se hace de la palabra 'verdad'; e ilustra el significado del predicado 'es verdadero' ${ }^{12}$. Es decir: cuando se dice que un juicio es verdadero, se quiere decir que, en efecto, concuerda con su objeto, aunque el concepto de 'verdad' no se agote, necesariamente, en la correspondencia (cf. Vanzo 2010: 162-166). Y lo que es más, que la definición nominal de verdad sea la adecuación del conocimiento con su objeto implica que cualquier teoría filosóficamente respetable de la verdad debe dar cuenta de esta relación. Y es así que el mismo Kant, con su doctrina de la verdad trascendental, intenta dar un fundamento filosófico a la definición nominal de verdad: "[Las] reglas del entendimiento (...) son incluso la fuente de toda verdad, es decir, de la concordancia de nuestro conocimiento con objetos" (KrV A237/B296, véase: Capozzi 2002: 427-428).

\footnotetext{
${ }^{11}$ Según indica Nenon, "las definiciones de conceptos de razón, como por ejemplo, el concepto de verdad, no son, para Kant, prescriptivas, sino descriptivas, y descriptivas en un sentido normativo: no describen lo que se piensa al escuchar una palabra, sino lo que se ha de pensar, pues pertenece a la cosa" (Nenon 1986: 30).

${ }^{12}$ En este sentido, Hanna describe la definición nominal de verdad como "estricta y analíticamente correcta, pero metafísica y epistémicamente neutral". En tanto que esta definición da cuenta de notas adscribibles a la noción de verdad, es analíticamente correcta, provee un modo de identificar qué tipo de cosas pueden caer bajo tal concepto, y -piensa Hanna- compromete a Kant con una versión, al menos débil, de la teoría de la correspondencia. Sin embargo, es metafísicamente neutra en tanto que no da cuenta como sí lo haría una definición real- de la posibilidad misma de la verdad, y epistémicamente neutra por no ser suficiente para conocerla según sus determinaciones internas y, en último término, por no ofrecer un criterio absoluto de diferenciación; esto es, por no constituir, a la vez, un criterio de verdad (Hanna 2000: 227, 233-234).
} 
Así pues, reconocer que la definición que Kant acepta de verdad es nominal implica que, aunque tal definición ofrece notas características del concepto y con ello posibilita su uso, no da cuenta de la esencia real, la posibilidad, y todas las consecuencias de la verdad y, por tanto, tampoco compromete con una teoría concreta sobre la misma; pero nos obliga a dar cuenta de esa definición como una característica del concepto. En este sentido, aun cuando no contemos con una exposición sistemática del término 'verdad trascendental', podemos adelantar, dada la aceptación kantiana de la definición de verdad, que ha de consistir, en algún aspecto, en la correspondencia del conocimiento con su objeto.

Sin embargo, como anunciábamos líneas arriba, la noción de 'verdad trascendental' aparece explícitamente sólo en dos lugares de la Crítica de la razón pura:

Todos nuestros conocimientos, empero, residen en el conjunto de toda la experiencia posible; y en la universal referencia a ella consiste la verdad trascendental, que precede a toda verdad empírica, y la hace posible (KrV A146/B185)

[...] sólo en [el hecho de] que estos conceptos expresan a priori las relaciones de las percepciones en toda experiencia, se conoce la realidad objetiva de ellos, es decir, su verdad trascendental, y [se la conoce], por cierto, independientemente de la experiencia, pero no independientemente de toda referencia a la forma de una experiencia en general, y a la unidad sintética, sólo en la cual pueden ser conocidos empíricamente los objetos (KrV A221-222/B269).

En estos fragmentos, si bien Kant no ofrece una definición precisa de la expresión en cuestión, señala, en cambio, una serie de características sobre ella: precede y posibilita la verdad empírica; consiste en la referencia a la experiencia posible; se conoce independientemente de la experiencia pero no de toda referencia a la forma de la experiencia en general; y es identificada con la realidad objetiva. Como se hará evidente a lo largo de esta exposición, todas estas caracterizaciones están estrechamente vinculadas entre sí y, aunque con diferentes matices, apuntan precisamente a la correspondencia del conocimiento con el objeto. Por lo pronto, comenzaremos con la noción de 'realidad objetiva', que, como consta en los fragmentos citados, Kant equipara explícitamente con 'verdad trascendental'.

'Realidad objetiva' (objective Realität) significa, en pocas palabras, referencia a un objeto ${ }^{13}$. Una representación cualquiera, por ejemplo, un concepto, tiene realidad objetiva si es posible referirlo a un objeto. Ahora bien, que se pueda establecer referencia a un objeto implica que tal objeto puede sernos dado, es decir, que es posible referir su representación a la experiencia (KrV A155-156/B194195). Esta referencia puede cumplirse de distintos modos. El modo más inmediato consiste en la relación que los conceptos empíricos guardan con sus objetos. La realidad objetiva de estos conceptos no es problemática, pues tenemos a la mano la experiencia, que da cuenta de la legitimidad de tales conceptos ( $\mathrm{KrV}$ A84/B116-117). Así, por ejemplo, teniendo frente a mí una mesa, compruebo inmediatamente que el concepto 'mesa' tiene efectivamente un objeto al que se dirige, que lo dota de sentido y de significación. Tal relación no es problemática porque, de hecho, tales conceptos se extraen de la experiencia. Así, en su propio origen, se cumple la exigencia de la relación con un objeto de experiencia: la 'posibilidad' de referir dichos conceptos a objetos es patente dado que, de facto, se dirigen a objetos. Sin embargo, esta misma exigencia es válida para los conceptos puros:

\footnotetext{
${ }^{13}$ En la literatura kantiana suele distinguirse tradicionalmente entre validez objetiva (objective Gültigkeit) y realidad objetiva (objective Realität). En términos generales, la primera consistiría en la aplicabilidad de las categorías a objetos en general, y se demuestra en la necesidad de las categorías como condiciones de la experiencia (aunque Kant habla también de validez objetiva de tiempo y espacio: $\mathrm{KrV}$ A20/B44, A35/B52). La segunda, en cambio, concerniría a la relación de los conceptos con objetos efectivos. Sin embargo, no encuentro bases suficientes para esta distinción. No me es posible profundizar en esta discusión, pero basta señalar que, en general, Kant describe ambos términos como la referencia a la posibilidad de la experiencia (validez objetiva, e.g. KrV A93/B126, A156/B195; realidad objetiva, e.g. KrV A157/B197, A217/B264). Me interesa señalar, sobre todo, que 'realidad objetiva' no se puede entender como referencia a un objeto efectivo (wirklich): en el pasaje en que Kant identifica esta noción con verdad trascendental, dice que se conoce "independientemente de la experiencia, pero no independientemente de toda referencia a la forma de una experiencia en general" (KrV A221-222/B269). De modo similar, critica a Hume el confundir la referencia a la experiencia posible -identificada en el mismo pasaje con la realidad objetiva- con la experiencia efectiva (wirkliche Erfahrung) (cf. KrV A766/B794). En la Crítica, en algunos pasajes señala que se conoce la realidad objetiva en la referencia a la experiencia efectiva (KrV A84/B116-117, B291). Pero esto no significa que sólo en la experiencia efectiva se conozca la realidad objetiva. Es una ratio cognoscendi, pero no su ratio essendi. En cambio, se lee en varios pasajes que la realidad objetiva se basa en la referencia a la posibilidad de la experiencia (KrV A95, A156-157/B195-196, A217/B264, A221/B268, A221-222/B269). Howell provee evidencia textual relevante que muestra el uso intercambiable que Kant hace de realidad objetiva y validez objetiva (Howell 1992: 363n, 366n, también Rosales 2000: 121).
} 
éstos son 'conceptos vacíos', 'meras formas de pensamiento' en tanto nuestra intuición no las dote de sentido y significado ( $\mathrm{KrV}$ B148, B150, B288, A279/B335). De este modo, éstos exigen también poder ser referidos a objetos, si es que han de tener un uso legítimo. Sin embargo, dado que estos conceptos no son extraídos de la experiencia, es preciso probar la posibilidad de referirlos a objetos, tarea que Kant acomete, famosamente, a lo largo de la 'Deducción trascendental ${ }^{14}$. Ahí, Kant demuestra la posibilidad de referir estos conceptos a objetos de experiencia mostrando que la experiencia misma se basa en la síntesis efectuada por ellos (cf. KrV A156-157/B195-196) ${ }^{15}$. Así pues, en términos generales, es la relación con la experiencia, esto es, la posibilidad de referir a ella nuestras representaciones, donde se fundamenta la realidad objetiva de estas últimas: "la experiencia, como síntesis empírica, es, en su posibilidad, la única especie de conocimiento que le da realidad [Realität] a toda otra síntesis" $\left(\right.$ KrV A157/B196) ${ }^{16}$.

Ahora bien, aunque Kant utiliza el término 'experiencia' (Erfahrung) en sentidos diversos (cf. Gutiérrez 1985: 5-20), es preciso entenderla aquí -en tanto fundamento de la realidad objetiva de nuestras representaciones- en su sentido más técnico, es decir, como la relación de algo estrictamente empírico con las condiciones a priori del conocimiento (tanto sensible como intelectual). Esto es, es el material de las impresiones, dado según las formas puras de la sensibilidad, elaborado por el entendimiento puro (cf. KrV B12, A93-94/B125-126, A124-125, A126-128, B161, A146/B185, A156157/B195-196, A176/B218; Prol 4: 300). Teniendo esto en cuenta, debe ser claro que al decir que un concepto -sea empírico o puro- adquiere realidad objetiva según su referencia a un objeto de experiencia, no cabe pensar en un objeto independiente de nuestro entendimiento, sino en uno constituido como objeto, precisamente, a través de las categorías y las formas puras de la sensibilidad. De igual modo, lo meramente dado -independientemente de la unidad que imponen las facultades cognoscitivas humanas - tampoco puede ser garantía de realidad objetiva, pues carece, precisamente, de objetividad (cf. KrV A120) ${ }^{17}$.

Ahora bien, en palabras de Kant, no es necesariamente la experiencia efectiva la que dota de referencia a un objeto, sino la experiencia en su posibilidad (cf. KrV A157/B196). Que la condición de la realidad objetiva sea la experiencia posible quiere decir, en última instancia, que la referencia a un objeto se cumple -como denotan los fragmentos antes citados respecto a la verdad trascendentalen la referencia a la forma de la experiencia en general; esto es, en las condiciones sensibles y conceptuales del conocimiento. Por esto, Kant puede decir que la realidad objetiva o verdad trascendental "se conoce independientemente de la experiencia pero no de toda referencia a la forma de la experiencia en general". Por último, vale la pena anotar que la realidad objetiva de los conceptos empíricos, aunque -como se mencionaba líneas arriba- se prueba de facto en la referencia inmediata a la experiencia, reposa ultimadamente, según lo dicho, en la referencia a las condiciones que hacen posible esa experiencia ${ }^{18}$.

\footnotetext{
${ }^{14}$ No pretendo, por cierto, analizar aquí este texto. De momento, sólo me interesa analizar la noción de 'realidad objetiva'.

${ }^{15} \mathrm{La}$ realidad objetiva de los conceptos puros del entendimiento es probada en tanto que sólo mediante ellos es posible la experiencia. Así pues, ellos son 'puras condiciones a priori para una experiencia posible', y a la vez, sólo en tal experiencia "puede basarse la realidad objetiva de ellos" (KrV A95; cf. A310/B367). Kant expresa famosamente esta aparente circularidad en la 'Doctrina del método' a propósito del principio de causalidad - pero que vale para todas las condiciones a priori de la experiencia-, a saber, que es sólo válido en su referencia a la experiencia, y a la vez es el fundamento de ella; con lo que tiene "la propiedad particular de que ella misma hace posible, ante todo, el fundamento de su demostración, a saber, la experiencia, y siempre debe ser presupuesta en ésta" (KrV A737/B765. Ver también A93/B126 y A95). Al respecto, Rosales señala que, si bien las categorías posibilitan la verdad de la experiencia y de su objeto, sólo tras semejante posibilitación "pueden la experiencia y su objeto, en tanto ya fundadas, retrorreferirse a las categorías y concordar con ellas, es decir, hacerlas verdaderas. En ello no tiene lugar ningú recíproco fundarse circular entre la experiencia y el objeto, por un lado, y las categorías por el otro, sino las categorías posibilitan a la experiencia y su objeto y, por decirlo así, se posibilitan a través de ellos a sí mismas como objetivamente verdaderas" (Rosales 2000: 130).

${ }^{16}$ Para ejemplificar el término 'realidad objetiva' he recurrido aquí a los conceptos, pero lo mismo es válido para las formas puras de la sensibilidad; por ejemplo: "[el espacio y sus determinaciones] tienen realidad objetiva, es decir, se refieren a cosas posibles, porque contienen en sí, a priori, la forma de la experiencia en general" (KrV A221/B268)

${ }^{17}$ En efecto: lo absolutamente novedoso del planteamiento kantiano sobre el objeto consiste en que son las facultades del sujeto las que dotan de objetividad al objeto. Antes del giro copernicano, el objeto se había de entender como objeto en tanto que es independiente del sujeto que lo conoce: su objetividad radica en su ser una cosa en sí. En Kant, en cambio, es la acción activa del sujeto -en tanto que provee las formas según las que se conoce- la que logra hacer un objeto aquello a lo que se dirige, al dotarlo de unidad, y esa unidad puesta según cierta necesidad. Pero ningún objeto trascendente, correspondiente a cierta intuición, puede ser intuido como tal por la sensibilidad. Por ello, en Kant, la objetividad de un objeto depende de que se ajuste a las condiciones necesarias del modo específico de conocer del sujeto.

18 "El concepto puro de este objeto trascendental (...) es aquello que en todos nuestros conceptos empíricos puede suministrar, en general, referencia a un objeto, es decir, realidad objetiva" (cf. KrV A109).
} 
Dicho todo esto, queda por aclarar de qué modo la expresión 'verdad trascendental' ha de equipararse con 'realidad objetiva' y, con ello, mostrar en qué sentido consiste ella en 'la universal referencia al conjunto de toda la experiencia posible'. Un paso inevitable para dilucidar el sentido de la expresión que nos ocupa es recurrir a la definición nominal de verdad, esto es, 'la concordancia del conocimiento con su objeto'. Si es verdad, como hemos sostenido antes, que la definición nominal -a pesar de constituir una descripción limitada del término- ofrece características que en efecto le pertenecen y, sobre todo, que una teoría de la verdad ha de dar cuenta de la relación que tal definición describe, entonces debe establecerse el modo en que la 'verdad trascendental' constituye una relación de concordancia entre el conocimiento y su objeto. Como enseguida veremos, es precisamente esta definición nominal la que aclara el sentido en que Kant puede asimilar 'realidad objetiva' y 'verdad trascendental'.

Con esto último en mente, la trama de la relación entre 'realidad objetiva' y 'verdad trascendental' se descubre en un pasaje de la 'Deducción trascendental' de la primera edición ${ }^{19}$ que señala:

El concepto puro de este objeto trascendental (que efectivamente es siempre idéntico $=\mathrm{X}$ en todos nuestros conocimientos) es aquello que en todos nuestros conceptos empíricos puede suministrar, en general, referencia a un objeto, es decir, realidad objetiva. Ahora bien, este concepto no puede contener ninguna intuición determinada, y no concierne a nada más que a aquella unidad que debe encontrarse en un múltiple del conocimiento, en la medida en que tiene referencia a un objeto. Pero esa referencia no es otra cosa que la unidad necesaria de la conciencia, y por tanto también de la síntesis del múltiple [efectuada] por la función común de la mente, de enlazarlo en una representación. Ahora bien, como esta unidad debe ser considerada como necesaria a priori (pues de otro modo el conocimiento se quedaría sin objeto), la referencia a un objeto trascendental, es decir, la realidad objetiva de nuestro conocimiento empírico, se basará en la ley trascendental de que todos los fenómenos, en la medida en que mediante ellos han de sernos dados objetos, deben estar bajo reglas a priori de la unidad sintética de ellos, sólo según las cuales es posible la relación de ellos en la intuición empírica, es decir, que ellos deben estar, en la experiencia, sometidos a condiciones de la unidad necesaria de la apercepción, tal como en la mera intuición [deben estar sometidos] a las condiciones formales del espacio y del tiempo; y aún más: que [sólo] mediante aquella se hace posible, ante todo, cualquier conocimiento ( $K r V$ A109110).

Si bien Kant -como vimos líneas arriba- fundamenta en varias ocasiones la realidad objetiva en función de la referencia a la experiencia en general (KrV A95, A156-157/B195-196, A217/B264, A221-222/B269, A310/B367), en este pasaje describe en dos ocasiones la realidad objetiva (del conocimiento empírico) como la referencia a un objeto: "[e]1 concepto puro de este objeto trascendental (...) es aquello que en todos nuestros conceptos empíricos puede suministrar, en general, referencia a un objeto, es decir, realidad objetiva" y "(...) la referencia a un objeto trascendental, es decir, la realidad objetiva de nuestro conocimiento empírico (...)”. Esto no debe sorprendernos si atendemos a la sentencia kantiana que indica que las condiciones de posibilidad de la experiencia son, a la vez, las condiciones de posibilidad de los objetos ( $\mathrm{KrV}$ A158/B197). Lo que cabe destacar es que el objeto en el que se ha de cumplir la referencia es el "objeto trascendental"

\footnotetext{
${ }^{19}$ Aunque este pasaje no aparece en la segunda edición, es completamente coherente con ella. El concepto que a continuación se analiza (objeto trascendental) es el mismo que Kant define en la segunda edición de la siguiente manera: "Objeto, empero, es aquello en cuyo concepto está reunido lo múltiple de una intuición dada. Ahora bien, toda unión de las representaciones exige unidad de la conciencia en la síntesis de ellas. En consecuencia, la unidad de la conciencia es lo único que constituye la referencia de las representaciones a un objeto, y por tanto, la validez objetiva de ellas, y en consecuencia, que ellas lleguen a ser conocimientos; y sobre ella, en consecuencia, reposa la posibilidad misma del entendimiento" ( $\mathrm{KrV}$ B137). Las afirmaciones hechas en el pasaje de la primera edición que aquí refiero pueden encontrarse a lo largo de $\$ 17-\$ 18$ de la segunda edición (KrV B136-140).

${ }^{20}$ Estas afirmaciones suponen que no entiendo 'objeto trascendental=X', como hacen algunos intérpretes, como una referencia a la cosa en sí, sino al objeto en general, esto es, a la síntesis que ejercen las categorías sobre las formas puras de la intuición, haciendo abstracción de todo contenido empírico. Ciertamente, como reconocen la mayoría de los intérpretes, hay un uso ambiguo del término 'objeto trascendental', a veces entendido como la unidad de la síntesis categorial, a veces como una referencia a la cosa en sí. Sin embargo, los pasajes pertinentes en A105-110 no dejan lugar a dudas de que Kant busca tematizar un concepto abstracto y general de la unidad de lo múltiple en el conocimiento de un objeto. Por otra parte, cabría tomar este último sentido de 'objeto trascendental' como el origen (para nosotros) de la noción de una cosa en sí, sin identificarlo con ella: “(...) la apercepción, y con ella, el pensar, precede a toda posible ordenación determinada de las representaciones. Por consiguiente pensamos algo en general, y lo determinamos, por un lado, sensiblemente, pero distinguimos el objeto en general, representado in abstracto, de esta manera de intuirlo; y entonces nos queda una manera de determinarlo meramente por el pensar, la cual es, por cierto, una mera forma lógica sin contenido, pero nos parece ser, sin embargo, una manera como el objeto existe en sí mismo (noumenon), sin considerar la intuición, que está limitada a nuestros sentidos" ( $\mathrm{KrV}$ A289/B345-346). De este modo, la ambigüedad entre aquellos dos
} 
Este objeto, como se indica en el pasaje citado, no contiene ninguna intuición determinada y no concierne más que a la unidad que subyace a cualquier objeto. Pero en la medida en que lo dado empíricamente se conforma con este concepto, es que adquiere realidad objetiva. Lo que en este pasaje se pone de relieve es que la experiencia, si se atiende sólo a lo que hay de empírico en ella, no tiene realidad objetiva. Ésta sólo se logra si lo dado puede articularse bajo la unidad que el concepto de un objeto impone. Sin la actividad sintética del entendimiento, lo dado empíricamente carece de objetividad; pero también carece de ella el concepto intelectualmente puro de un objeto, si no pudiese referirse a lo dado.

De este modo, lo propio de la referencia objetiva es la articulación de la unidad impuesta por el entendimiento con la posibilidad de la intuición de algo dado. Así, la referencia a un objeto (al objeto en general, objeto trascendental) designa la realización de la síntesis inscrita en el concepto de objeto atendiendo a la forma de nuestra intuición sensible -aunque sin tener en cuenta ninguna intuición empírica concreta-. Sólo en la medida en que los fenómenos estén sometidos a la unidad necesaria de la apercepción y a las condiciones formales del espacio y del tiempo es que -como subraya Kant- se hace posible, ante todo, cualquier conocimiento.

Todo lo que hemos apuntado ahora pretende poner al descubierto la pieza clave que faltaba para articular la identificación que Kant hace entre 'realidad objetiva' y 'verdad trascendental' mediante la definición de verdad como 'concordancia entre objeto y conocimiento'. Esta pieza no es otra cosa que la noción de un objeto en general (o trascendental), tomado como la articulación de las condiciones sensibles y conceptuales del conocimiento ${ }^{21}$. Según todo esto, la verdad trascendental es aquella concordancia que se establece entre la totalidad de las condiciones de la objetividad (categorías y formas de la intuición) y nuestros conocimientos. De cara al pasaje recién citado, nuestros conocimientos empíricos tienen realidad objetiva -verdad trascendental-por su referencia a este objeto. Pero es también la referencia a este objeto, en la medida en que constituye a su vez la posibilidad de la experiencia, lo que dota de verdad a nuestros conocimientos a priori. La denominación de esta relación como un tipo de verdad es lo que permite a Kant decir que las categorías y el conocimiento a priori en general son verdaderos y hablar, en general, de verdad aún antes de toda experiencia ${ }^{22}$ (pero "no independientemente de toda referencia a la forma de una experiencia en general") y, por tanto, antes de toda verdad empírica ${ }^{23}$. Así pues, la experiencia empírica en general es verdadera -trascendentalmente-, porque concuerda con todas las condiciones a priori de la objetividad, esto es, con el objeto trascendental. Pero también todas las representaciones a priori que hacen posible la experiencia poseen verdad trascendental por la misma razón: concuerdan con este objeto en general, que no es otra cosa que el conjunto de condiciones de la objetividad. El objeto en general se adecúa a las condiciones a priori de posibilidad del conocimiento; y el conocimiento empírico se ha de adecuar al objeto en general si es que ha de ser conocimiento para nosotros. Así pues, la noción de un objeto en general queda como un término medio entre las condiciones de posibilidad de la experiencia y la experiencia misma, definido y limitado por las primeras y definiendo y limitando a la segunda; realizando a las primeras y realizado por la segunda; y a la vez, y según esta definición, limitación y realización recíproca, dota de verdad a los términos con los que está en relación por ambas partes ${ }^{24}$.

sentidos de "objeto trascendental" pueden interpretarse no como un equívoco, sino como un paso en la unificación sistemática del idealismo trascendental (cf. Beade 2009: 83-118).

${ }^{21}$ Es preciso insistir en que no nos referimos a objeto concreto alguno. La identidad que Kant traza entre el objeto trascendental y las condiciones de posibilidad de la experiencia (mediante la relación de ambos con la expresión 'realidad objetiva') se puede entender comenzando con la experiencia, y retrotrayéndonos a sus condiciones: dado cualquier objeto empírico concreto, si abstraemos de él todo lo que es dado por la experiencia empírica (datos sensibles, notas conceptuales empíricas) al final no queda más que su definición como objeto según las categorías y su referencia al espacio y tiempo como formas de su intuición. Este objeto definido por las categorías, en referencia a tales formas, es precisamente el objeto trascendental=X, (idéntico para todo objeto empírico). Pero se descubre, a la vez, que sus elementos (categorías y formas puras de la intuición) son precisamente las condiciones de posibilidad de la experiencia.

${ }_{22}^{2}$ Por ejemplo, en KrV A124-125, A128, A157-158/B196-197, KrV A236-237/B295-296.

${ }^{23}$ De este modo, si bien es cierto - como indica Arias- que "la verdad trascendental consiste en la necesaria concordancia de la objetividad de los objetos empíricos con los principios ontológicos del entendimiento", esta verdad no se reduce a tal concordancia, pues abarca también aquella que se da entre todas las condiciones de posibilidad de la experiencia en general y el objeto trascendental, y que realizan y restringen, precisamente, a este último (Arias Albisu 2012: 19). La misma crítica vale para Palacios 2013: 133-135.

${ }^{24} \mathrm{Al}$ hablar del objeto en general como un término medio no pretendo, en modo alguno, hacer de él una representación hipostática.

Nuevamente, este objeto es sólo la condición de cognoscibilidad de los objetos. Al tratarlo aquí como un término medio, sólo 
Al principio de esta sección señalábamos que las distintas caracterizaciones que Kant hace de la verdad trascendental apuntan a lo mismo: la identificación con la 'realidad objetiva', su descripción como la 'referencia a la experiencia posible' y el que se conozca "independientemente de la experiencia pero no de toda referencia a la forma de la experiencia en general". El hilo conductor entre estas tres descripciones ha quedado claro al mostrar que Kant describe la realidad objetiva, en primera instancia, como la referencia a la experiencia posible. Pero, según vimos, en otras ocasiones Kant describe la realidad objetiva en función de su relación con el objeto trascendental. Aunque ya se ha señalado la equivalencia establecida entre las condiciones de posibilidad de la experiencia y las de los objetos (KrV A158/B197) como clave para resolver esta ambigüedad, es oportuno traer a colación un fragmento que nos ayudará ahora a esbozar una versión más acabada de este tema:

[P]uesto que la experiencia, como síntesis empírica, es, en su posibilidad, la única especie de conocimiento que le da realidad a toda otra síntesis, ésta, como conocimiento a priori, posee verdad (concordancia con el objeto) sólo porque no contiene nada más que lo que es necesario para la unidad sintética de la experiencia en general (KrV A157-158/B196-197).

Este pasaje aparece, precisamente, sólo un par de líneas antes de establecerse la equivalencia entre condiciones de posibilidad de experiencia y de objetos de experiencia. Pero lo que me interesa resaltar es, específicamente, la relación que Kant establece aquí entre 'verdad' y 'experiencia'. Lo primero que cabe destacar es que la palabra 'verdad' debe interpretarse como 'verdad trascendental'. Dado que Kant está hablando de la verdad de una síntesis como conocimiento a priori, es evidente que no puede referirse ni a la verdad formal (por ser síntesis) ni a la verdad empírica (por ser a priori). No sólo por eliminación se hace evidente esta conclusión: esta síntesis posee verdad porque contiene sólo lo necesario para la unidad sintética de la experiencia en general. Y es precisamente la referencia a la experiencia posible, como hemos visto hasta ahora, una de las características que Kant atribuye a la verdad trascendental.

En segundo lugar, es imposible pasar por alto que Kant ofrece expresamente una aclaración del término. ¿Por qué resulta relevante para Kant introducir aquí un paréntesis que aclare que la verdad es el acuerdo (Einstimmung) con el objeto? Nuevamente, es preciso señalar que al hablar de 'objeto' Kant no puede referirse aquí a un objeto empírico. Basta con señalar que, si se admite que 'verdad' en este contexto es 'verdad trascendental', se sigue necesariamente que 'objeto' se refiere aquí a un 'objeto en general', esto es, al concepto de objeto bajo las condiciones formales de la intuición ${ }^{25}$. Sin alterar el sentido del pasaje podemos reformularlo así: "una síntesis a priori concuerda con el objeto en general (posee verdad trascendental) porque contiene sólo todo lo necesario para la unidad sintética de la experiencia en general". Esto queda expresamente señalado por Kant cuando, líneas abajo, señala que los juicios sintéticos son posibles a priori "si referimos a un posible conocimiento de experiencia, en general, las condiciones formales de la intuición a priori, la síntesis de la imaginación, y la unidad necesaria de ella en una apercepción trascendental” ( $\mathrm{KrV}$ 158/B197).

De este modo se hace explícito algo que señalábamos antes: la referencia al objeto en general es, efectivamente, la referencia del conocimiento a aquellas condiciones que hacen posible a la experiencia en general. Las condiciones de posibilidad de la experiencia establecen el campo de experiencia posible: delinean el territorio en que es posible la experiencia y señalan sus límites. Pero este campo y sus límites se determinan, precisamente, estableciendo qué es lo que puede ser un objeto de experiencia. Así pues, es esta fórmula lo que permite a Kant, unas líneas después, tomar como equivalentes las condiciones de posibilidad de la experiencia y de los objetos de experiencia ${ }^{26}$.

pretendo poner de manifiesto que, aún antes de la experiencia empírica, ya está definida la objetividad como tal. Aún sin haber objetos concretos, ya está por completo señalado qué significa ser objeto. La posibilidad de un objeto ya ha sido definida, limitada y realizada. Se hablará más con mayor detenimiento sobre esta limitación y realización en la última parte de este trabajo.

${ }^{25}$ Paek subraya el hecho de que Kant escriba que la verdad es el acuerdo con $e l$ objeto, y no -como es usual- con su objeto. Lo que está de fondo, sostiene Chong, es precisamente la determinación del objeto (Paek 2005: 156).

${ }^{26}$ En última instancia, la identidad de las condiciones de posibilidad de la experiencia con aquellas de los objeto se concreta en el juicio. En la medida en que los principios del entendimiento puro regulan el modo de enlazar mediante categorías lo dado en la intuición -y con ello expresan la articulación de las condiciones de posibilidad de toda experiencia-, guían todo enlace sintético judicativo. Según esto, Flamarique señala: "estos principios que subyacen a los juicios van a ser simultánea e inseparablemente principios del ser de los objetos, ya que es en el juicio donde se presentan los objetos al sujeto cognoscente; su presentarse en el enlace categorial es, al mismo tiempo, su constituirse como tales objetos" (Flamarique 1991: 128). 
Con este pasaje se perfila, pues, con mucha más claridad la relación entre las nociones que habíamos expuesto: 'verdad trascendental', 'realidad objetiva' y 'experiencia posible'. A la luz de la definición de verdad trascendental como la concordancia con las condiciones a priori de la objetividad (con el objeto trascendental) se hacen nítidas las razones por las cuales Kant puede identificar verdad trascendental y realidad objetiva; puesto que esta última es, precisamente, la referencia a un objeto. Del mismo modo, se hace patente como es que tanto la referencia a la experiencia y la referencia al objeto convergen a la vez en la noción de 'realidad objetiva'. Sin embargo, veíamos también que Kant caracterizaba a la verdad trascendental como aquella que "precede a toda verdad empírica, y la hace posible". Si bien a lo largo de la exposición ya se ha dicho algo al respecto, se ilustrará esta cuestión con mayor claridad en las siguientes secciones al abordar el tema del criterio de verdad y la relación de la verdad trascendental con el conocimiento en general.

\section{Criterios de verdad y conocimiento a priori}

En la Introducción a la lógica trascendental, -en los mismos pasajes en que acepta la definición nominal de verdad- Kant niega la posibilidad de un criterio material y universal de verdad. En breves palabras, argumenta que un criterio, para ser universal, debe ser válido para todos los objetos y, por tanto, hacer abstracción de todo contenido de los objetos. Pero, para ser material, debe referirse, precisamente, a aquel contenido. Por ende, un criterio universal y material resulta, necesariamente, contradictorio (KrV A58-59/B83). Este planteamiento ha dado lugar también a discusión: hay autores que entienden que la imposibilidad de criterios universales y materiales es absoluta. Hay otros que, en cambio, sostienen que esta imposibilidad caracteriza sólo a la lógica general. La lógica trascendental sería, según ellos, precisamente la innovación kantiana que permite encontrar estos criterios, al ofrecer características que todo objeto debe compartir (categorías y formas de la intuición) ${ }^{27}$.

Ahora bien: el argumento kantiano respecto a la imposibilidad de criterios materiales y universales está, en efecto, enmarcada en la caracterización de la lógica general. Esta discusión es utilizada, de hecho, para distinguir entre la analítica y la dialéctica de dicha lógica. En efecto: la lógica sí cuenta con ciertos criterios universales de verdad, pero estos no son otros que la forma del conocimiento. Es decir, estos criterios universales son, en última instancia, solo criterios formales, que todo conocimiento ha de cumplir, pero que no bastan para la determinación material de la verdad y, por ende, son criterios negativos. Son, en otras palabras, criterios sine qua non de la verdad. La parte de la lógica que estudia estas reglas universales es la analítica. Sin embargo, en la medida en que se pretende hacer uso material de estos criterios, determinando ilegítimamente la verdad del conocimiento de manera positiva, es que se hace uso dialéctico de la lógica (KrV A59-62/B83-86).

Por otra parte, dado que la lógica trascendental -al contrario que la lógica general- no hace abstracción de todo el contenido de los objetos, tiene ciertos criterios que, sin ser meramente formales, son universales ( $\mathrm{KrV}$ A55-56/B79-80). Así pues, parecería en primera instancia que esta nueva lógica es capaz de proveer aquellos criterios universales y materiales de verdad que le son negados a la lógica general. Sin embargo, justo después de negar la posibilidad de utilizar de manera material los criterios formales de la lógica general, Kant hace una advertencia similar respecto de la lógica general, previniendo al señalar que "el uso de este conocimiento puro se basa en la condición siguiente: que se nos den en la intuición objetos a los que pueda aplicarse" (KrV A62/B87). Y acto seguido enfatiza:

Pero como es muy atractivo y seductor el servirse de estos conocimientos puros del entendimiento y de estos principios por sí solos, y aún más allá de los límites de la experiencia -que es, sin embargo, la única que nos puede suministrar la materia (objetos) a la que pueden ser aplicados aquellos conceptos puros del entendimiento (...) [S]e hace un uso indebido de ella [de la Analítica Trascendental] cuando se la hace valer como el organon de uso universal e ilimitado, y con el solo entendimiento puro se osa juzgar, afirmar y decidir sintéticamente acerca de objetos en general (KrV A63/B87-88).

\footnotetext{
${ }^{27}$ Entre quienes sostienen esta última postura podemos encontrar a Prauss (1969), Esterhuyse (1972: 284-285), Hofmeister (1972: 318 ) y Rosenkoetter (2009: 195). Sostienen, en cambio, que la imposibilidad de criterios universales y materiales suficientes aplica tanto para la lógica general como para la trascendental: Wagner (1977: 74), Nenon (1986: 55-56) y Schulz (1993: 129-132). Los autores que sostienen la primera postura han encontrado en el problema del criterio de verdad un rasgo de diferenciación entre la lógica general y lógica trascendental. Para una recapitulación sucinta de la discusión en torno al problema de la verdad como motivo para esta distinción, ver Vázquez Lobeiras (1998: 54-58).
} 
Del mismo modo que la lógica general hace abstracción de todo contenido del conocimiento, la lógica trascendental, a pesar de conservar cierto contenido del conocimiento, hace abstracción del contenido empírico, esto es, de su referencia a la intuición ( $\mathrm{KrV}$ A57/B81, A63/B8788). Y precisamente, independientemente de la intuición, el entendimiento no tiene uso posible, por lo que la lógica trascendental no es capaz tampoco de operar como un criterio universal y material suficiente para determinar la verdad del conocimiento. En última instancia, la lógica trascendental también carece de los elementos necesarios para determinar el contenido veritativo del conocimiento en general.

Desde mi punto de vista, es precisamente la noción de 'verdad trascendental' la que permite dirimir adecuadamente esta controversia. Adelantando varios pasos, lo que Kant niega a la lógica trascendental es la posibilidad de determinar positivamente la verdad empírica del conocimiento (aunque, como veremos, es -como la lógica general- criterio negativo de esta verdad). Sin embargo sí nos ofrece, en cambio, garantía de la verdad (trascendental) de nuestro conocimiento a priori. Así, en un pasaje de la introducción a la 'Analítica de los principios', Kant habla explícitamente de criterios universales y suficientes de la concordancia de objetos con las categorías:

[La filosofía trascendental] se ocupa de conceptos que deben referirse a priori a sus objetos; por consiguiente, la validez objetiva de ella no puede ser establecida a posteriori; pues ello dejaría enteramente intacta aquella dignidad de ella, sino que a la vez debe exponer, mediante $\operatorname{criterios}^{28}$ universales pero suficientes para su conocimiento, las condiciones para que puedan ser dados objetos en concordancia con aquellos conceptos; en caso contrario, carecerían de todo contenido, y por tanto, serían meras formas lógicas y no conceptos puros del entendimiento (KrV A136/B175).

No debe sorprendernos, según lo expuesto, que Kant hable aquí expresamente de criterios universales y suficientes de la concordancia con objetos. El contexto mismo de este pasaje indica ya de inicio a qué criterios se refiere aquí Kant. Este pasaje está en el marco de la introducción al esquematismo y al sistema de los principios puros. Y precisamente, en tanto que esquemas y principios puros son aquellos criterios que exponen las condiciones para que puedan ser dados objetos en concordancia con las categorías, son criterios de verdad (piensa así también Rosenkoetter 2009: 209-210). Pero hay que notar que aquí 'criterios de verdad' no es utilizado como convencionalmente lo hacemos. No son criterios para decidir si un conocimiento empírico dado es verdadero o falso. Esto es, no son criterios establecidos para dilucidar si, de hecho, existe ya una relación de concordancia entre nuestro conocimiento y un objeto determinado. Son, más bien, criterios que exponen las condiciones de tal relación, es decir, el modo en que se ha de trabar esa relación. Así pues, no prueban la verdad (si tomamos verdad en su acepción más común) de un conocimiento. Hacen posible la verdad del conocimiento en general ${ }^{29}$. Son criterios que explican, pues, el modo en que se han de articular objetos dados con las categorías. Si bien se pone el acento en el entendimiento como uno de los extremos de la relación - puesto que se habla de las categorías-, es necesario reconocer a la sensibilidad en el otro extremo, puesto que se habla de las condiciones de dación de los objetos. Así pues, lo que estos criterios exponen es cómo es que se pueden dar en la intuición objetos, o lo que es lo mismo, cómo pueden las categorías sintetizar lo dado en la intuición, dando lugar a objetos. Así, en un pasaje casi al final de la deducción de la primera edición se expresa la misma idea aquí expuesta, haciendo, sin embargo, mención expresa de ambas facultades y de la imaginación como la guía de su articulación:

Los dos extremos, a saber, sensibilidad y entendimiento, deben articularse necesariamente por medio de esa función trascendental de la imaginación; pues de otro modo, aquella daría, ciertamente, fenómenos, pero no objetos de un conocimiento empírico, y por tanto [no daría] experiencia alguna (KrV A124).

\footnotetext{
${ }^{28}$ Caimi y Ribas traducen Kennzeichen por 'características'. Esta traducción es correcta pero, dado que el término alemán conlleva el sentido de 'distintivo', 'señal' o 'marca', he preferido verterlo aquí como 'criterio', lo cual enfatiza, además, la relación de este pasaje con la discusión general de criterios universales y suficientes. Al hablar de 'criterio universal y suficiente', Kant emplea indistintamente Kriterium y Kennzeichen, como puede verse en los pasajes contenidos en KrV A57-59/B82-83 discutidos anteriormente en este trabajo.

${ }^{29}$ Con base en esto, Palacios identifica la verdad trascendental con la posibilidad real de un objeto de experiencia, y en consecuencia identifica el primer postulado del pensar empírico con el criterio de verdad trascendental (Palacios 2013: 128). Aunque esto es correcto, también es parcial, puesto que -como ya hemos adelantado, y trataremos con más detenimiento enseguida- la verdad trascendental no se predica exclusivamente del conocimiento empírico. Por esta razón creo que yerra cuando -páginas después- restringe el ámbito de la verdad trascendental a los juicios de experiencia y la identifica con la adecuación del objeto empírico a la forma de la experiencia en general (Palacios 2013: 133, 135 respectivamente).
} 
La sensibilidad da fenómenos, pero sin intervención del entendimiento no hay aún objeto alguno de conocimiento empírico. Para esto hace falta -prosigue el pasaje- que los fenómenos estén sometidos a conceptos, "que hacen posible la unidad formal de la experiencia, y con ella toda validez objetiva (verdad) del conocimiento empírico" (KrV A124-125; cf. Prol 4:375). En el fragmento anterior (nos referimos a KrV A136/B175) Kant enfatizaba que las categorías, si no fueran puestas en concordancia con objetos dados, no serían más que formas lógicas. En este último pasaje, en cambio, se pone el acento en la otra facultad: la sensibilidad, independientemente del entendimiento, tampoco puede dar cuenta de objetos. Así pues, los objetos, como tales, no son representaciones propias ni de la sensibilidad ni del entendimiento tomados independientemente. Sólo en la medida en que ambas facultades se articulan es que son posibles los objetos en general. En la medida en que principios puros y esquemas proveen la posibilidad y la guía de tal articulación, es que son criterios de la concordancia con el objeto. Es decir, son criterios de verdad trascendental. Sólo en razón de estos criterios -en la medida en que posibilitan la forma de al experiencia en general, esto es, al objeto en general- es que podemos decir que el conocimiento a priori es verdadero. Y además, como concluye este último pasaje, en virtud de esta articulación entre sensibilidad y entendimiento es que se hace posible la verdad del conocimiento empírico. Pero, precisamente, no se hace verdadero el conocimiento empírico, se hace 'posible' su verdad (cf. Paek 2005: 154-156).

Antes de abordar de lleno esta última cuestión, vale la pena volver una vez más al pasaje en que Kant señalaba que era imposible un criterio universal y suficiente de verdad. En aquel pasaje, Kant negaba la posibilidad de tal criterio dado que la universalidad del criterio implica hacer abstracción de todas las diferencias entre los objetos. Pero la verdad, en tanto que se determina según la concordancia del conocimiento con su objeto, ha de tener en cuenta tales diferencias. Es imposible un criterio universal y suficiente dado que ha de abstraer y no abstraer, a la vez, de toda diferencia entre los objetos. Aquel pasaje estaba a las puertas de la 'Analítica trascendental'. Sólo tras la Analítica se muestra la posibilidad de dar cuenta de una noción de objeto que prescinde de las diferencias específicas de cada objeto particular, y que a la vez da cuenta del modo de ser objeto de todos aquellos objetos. Sólo este sentido de objeto hace posible comprender la noción de 'verdad trascendental'. Es claro, por tanto, que la verdad a la que Kant se refiere al negar la posibilidad de un criterio suficiente y universal de verdad es la verdad empírica. Mientras que criterios universales y suficientes de verdad empírica son imposibles, tales criterios son posibles para la verdad trascendental, ya que el objeto con el que se ha de establecer la concordancia es siempre el mismo. Pero, aun así, ¿son realmente tan universales y suficientes estos criterios?

En la "Introducción a la lógica trascendental", justo después de negar la posibilidad de un criterio universal y suficiente de verdad, Kant señala que, "en lo que concierne al conocimiento según la mera forma (dejando de lado todo contenido) está claro que una lógica, en la medida en que expone las reglas universales y necesarias del entendimiento, debe presentar en esas mismas reglas criterios de la verdad" (KrV A59/B83-84). Kant está introduciendo aquí la idea de la lógica general (o formal) como criterio de verdad negativo. Todo lo que no concuerde con las leyes de la lógica general no puede abrigar pretensiones de verdad. Pero dado que estas leyes hacen abstracción por completo del objeto, no son suficientes para dilucidar positivamente la verdad del conocimiento. Como ya señalábamos antes, la lógica trascendental guarda paralelismo, en este respecto, con la lógica general. Aunque la lógica trascendental se ocupa de la relación con el objeto en general, también prescinde de lo dado empíricamente y, por tanto, de las diferencias específicas de los objetos empíricos y de sus conocimientos respectivos. La lógica trascendental, por tanto, ofrece también criterios que todo conocimiento ha de satisfacer para ser verdadero -ya que, de hecho, prescribe las condiciones de posibilidad de concordancia con un objeto-, pero no brinda, en cambio, criterios para decidir si un conocimiento específico es verdadero o no; esto es, si hay o no verdad empírica. De este modo, la verdad trascendental precede y posibilita a la verdad empírica, pero sus criterios no son suficientes para la determinación de esta última ${ }^{30}$. Los alcances y límites de estos criterios quedan expresados muy claramente por Kant en un pasaje de la "Doctrina del método":

\footnotetext{
${ }^{30}$ En este sentido, Kant llega a decir que las categorías "no solamente son verdaderas a priori, sino que son incluso la fuente de toda verdad, es decir, de la concordancia de nuestro conocimiento con objetos, porque contienen en sí el fundamento de la posibilidad de la experiencia, como conjunto de todo el conocimiento en el que nos pueden ser dados objetos, [pero] aun así no nos parece suficiente que se enseñe que es verdadero, sino [que pretendemos que se nos enseñe] lo que uno apetece saber" (KrV A237/B296).
} 
Que la luz de sol, que ilumina la cera, a la vez la funde, mientras que endurece la arcilla, [es algo que] ningún entendimiento podría adivinar, y aún menos podría inferir de acuerdo con una ley, a partir de conceptos que previamente tengamos de estas cosas; y sólo la experiencia puede enseñarnos tal ley. Por el contrario, en la lógica trascendental hemos visto que si bien nunca podemos ir inmediatamente más allá del contenido de un concepto que nos es dado, podemos sin embargo conocer, enteramente a priori, pero con referencia a un tercero, a saber, a la experiencia posible, y por tanto, en efecto, a priori, la ley de la conexión con otras cosas. Por consiguiente, si la cera que antes era sólida se funde, puedo conocer a priori que algo debe haber precedido (p. ej. el calor del sol), de lo cual esto se siguió de acuerdo con una ley constante, aunque yo, sin experiencia, no pueda conocer de manera determinada, a priori y sin ser instruido por la experiencia, ni la causa, a partir del efecto, no el efecto, a partir de la causa $(\mathrm{KrV}$ A765-766/B793-794).

La universalidad y suficiencia de los criterios de verdad trascendental son tan amplias como el papel que ellos mismos juegan en la constitución de la experiencia en general. Así pues, su aplicación es universal pues todo objeto de experiencia está constituido bajo condiciones impuestas $a$ priori y, por ello, toda experiencia particular tendrá que poder responder, por ejemplo, al criterio de causa. Pero su suficiencia está también delimitada según esta misma función como constitución de la experiencia en general y, por tanto, no pueden dar cuenta de las peculiaridades de los objetos en específico, en tanto que tales peculiaridades, aunque se articulen (sean unificadas y sintetizadas) según nuestras facultades, no tienen su origen en estas últimas, pues nos son dadas. De este modo, las leyes de la lógica trascendental no son criterios que puedan ayudar a dilucidar la verdad de un conocimiento empírico. No son criterios útiles para saber si es verdad que la causa de que la cera se derrita es el sol. En cambio, son útiles para saber que, si la cera se ha derretido, debe haber una causa. En el ámbito de la experiencia empírica son, por tanto, criterios universales, pero no suficientes.

Pero, si esto es así, ¿por qué habla Kant entonces en el pasaje en cuestión (KrV A136/B175) de criterios 'universales pero suficientes' (allgemeinen, aber hinreichenden Kennzeichen)? Para aclarar esto, nos habremos de valer nuevamente de una comparación con la lógica general. Aunque Kant es enfático en señalar que el principio de contradicción "es un criterio universal, pero sólo negativo, de toda verdad" (KrV A151/B190; cf. A59/B84), concede, sin embargo, que es posible hacer uso positivo de él; esto es, no sólo para excluir la falsedad y el error, sino también para conocer la verdad. Pero este uso se restringe a los juicios analíticos. Dado que la verdad de un juicio analítico se refiere meramente a la relación de las notas puestas en los conceptos del sujeto y del predicado, esta verdad se puede determinar sin alusión a un elemento externo al juicio mismo. Por ello podemos admitir "al principio de contradicción como el principio universal y enteramente suficiente [allgemeine und völlig hinreichende Principium] de todo conocimiento analítico; pero su autoridad y su utilidad no van tampoco más allá de [ser] un criterio suficiente de la verdad [eines hinreichenden Kriterium der Wahrheit]" (KrV A151/B191). Así pues, Kant señala expresamente la suficiencia y universalidad del principio de contradicción como criterio de verdad; pero a la vez restringe esta suficiencia al ámbito del conocimiento analítico, esto es, de la verdad formal ${ }^{31}$.

Del mismo modo que establece un principio supremo del conocimiento analítico, Kant establece, para el conocimiento sintético, la referencia a las condiciones de la experiencia como su principio supremo: "todo objeto está sometido a las condiciones necesarias de la unidad sintética de lo múltiple de la intuición en una experiencia posible" (KrV A158/B197). Y, asimismo, la lógica trascendental corre un destino paralelo a la lógica general: tal como el principio de contradicción es condición ineludible de todo conocimiento, pero su validez como criterio positivo de verdad se constriñe al conocimiento analítico, así también los criterios de verdad trascendental deben cumplirse para que cualquier conocimiento sintético - a priori o de experiencia- pueda ser verdadero (pueda referirse a un objeto), pero sólo han de ser tomados como criterios positivos dentro de los límites de

\footnotetext{
${ }^{31}$ Hanna construye su interpretación sobre tres diferentes criterios de verdad apoyándose en esta doctrina del criterio formal de la verdad. Entiende que podemos aplicar lo dicho sobre el conocimiento analítico a los otros tipos de conocimiento. De este modo, habría tres criterios de verdad, restringidos respectivamente a tres tipos de conocimiento: uno al conocimiento analítico, otro al conocimiento sintético a priori, y otro al conocimiento sintético a posteriori (Hanna 2000: 244-248). Aunque esta lectura reconoce acertadamente que existen tres sentidos distintos de verdad (formal, trascendental y empírica), reposa en buena medida en la interpretación de que la negativa de un criterio universal y suficiente ha de entenderse como la postulación de tres criterios (uno para cada tipo de verdad), y desestima el hecho de que, en el ámbito de la verdad empírica, las diferencias entre los objetos impiden la suficiencia de criterio alguno, que es lo que el argumento contra el criterio universal y suficiente señala. Por otra parte, si bien su descripción del criterio de verdad empírica se basa en algunos pasajes de la Crítica (KrV Bxli nota, A191/B236, A451/B479), tales pasajes no hablan de un criterio de verdad para conocimientos empíricos concretos, sino de la distinción entre la forma de la experiencia efectiva en general y la ilusión, por ejemplo, de un sueño.
} 
lo a priori. No obstante, en la medida en que se restrinjan a estos límites, son criterios suficientes. En este sentido podemos decir que los juicios sintéticos a priori, así como las categorías o el espacio y el tiempo son verdaderos ${ }^{32}$; pero, precisamente, sólo en función de su referencia al objeto en general. Esto es, son verdaderos 'trascendentalmente'. Así, en la verdad trascendental se cumple plenamente la noción de verdad como 'concordancia con un objeto'. Y no sólo eso, sino que en ella se fundamenta la posibilidad de toda concordancia con un objeto. Ella es el fundamento y fuente de toda verdad ${ }^{33}$.

\section{La cartografía de la verdad}

Como señalábamos al inicio de este texto, no deja de ser llamativo que la revolución copernicana que Kant protagoniza estribe en la inversión de los términos de la relación de verdad, esto es, del conocimiento y el objeto. Pero es precisamente con la pregunta por la posibilidad de esta relación (y por ende, con la pregunta por la posibilidad de la verdad) con que la investigación crítica inicia, diez años antes de la publicación de la Crítica de la razón pura. En su famosa carta a Herz, Kant emprende el camino hacia la filosofía crítica intentando dar cuenta de una 'carencia esencial' descuidada antes por él y por la filosofía en general, "y que de hecho contiene la clave del enigma, hasta ahora indescifrado incluso para ella misma, de la metafísica (...): ¿cuál es el fundamento sobre el que reposa la relación de la representación con el objeto?" (Br 10: 130). Kant se preguntaba, en esa carta, cómo es que el entendimiento podía formarse a priori conceptos que concordaran con las cosas, cómo podía proyectar principios reales sobre su posibilidad, que, además, concordaran con la experiencia sin provenir de ella; cuestiones que, escribía Kant: "dejan siempre una insuperable oscuridad en relación con nuestra facultad intelectiva: de dónde puede venirle la concordancia con las cosas mismas" (Br 10:131).

Parte del camino crítico consistió en suspender la búsqueda de la concordancia con las 'cosas mismas' ${ }^{34}$. Pero, pagado este costo, la lógica trascendental ofrece una respuesta a estas

\footnotetext{
${ }^{32}$ Véase KrV A128, A156-157/B195-196, A221/B268, A221-222/B269, A237/B296. (En algunos de estos pasajes, Kant no habla expresamente de verdad, sino de realidad objetiva.) Aunque la verdad se predica en primer lugar de los juicios (KrV A293/B350, Refl 2252 16: 286) y en consecuencia Kant dice que la verdad y el error no se pueden encontrar ni en los conceptos ni en las intuiciones (V-Lo/Blomberg 24: 83, V-Lo/Dohna 24: 720), en varios lugares de la Crítica afirma explícitamente que las categorías son verdaderas. Aunque la restricción de la verdad al juicio es estricta en el ámbito de la verdad empírica, la amplitud de la noción de 'verdad trascendental' y su conformidad con la 'realidad objetiva' permiten hablar de la verdad de las categorías y, en general, de las condiciones de posibilidad de la experiencia, contra interpretaciones que limitan la predicación de la verdad a juicios, por ejemplo Underwood (2003: 5), Hanna (2000: 228). A propósito de esto, Rosales apunta que es posible para Kant hablar de verdad en este sentido amplio (verdad de juicios, de conceptos o de intuiciones) al entenderla como la concordancia de la representación con su objeto. Esto es porque, en contra de la tradición escolástica y moderna, Kant concibe el conocimiento no sólo como juicio sino también como representación simple. Este es el desenlace de la investigación kantiana, a partir de mediados de la década de los 60 , sobre el carácter y posibilidad de representaciones sintéticas a priori. Esta reflexión condujo a Kant -concluye Rosales- a considerar la realidad objetiva de tales representaciones también como una clase de verdad en tanto concordancia (Rosales 2000: 118-119).

${ }^{33}$ Decir que la verdad trascendental es fundamento y fuente de toda verdad significa que no sólo fundamenta y posibilita a la verdad empírica, sino también a la verdad formal. Esto resulta contraintuitivo, si se considera que la verdad formal es más abstracta y condición previa de la verdad trascendental: ningún juicio puede carecer de verdad formal y a la vez ser trascendentalmente verdadero, pero lo contrario si puede suceder (en los juicios analíticos o en los juicios que expresan ilusiones dialécticas). Este tema merece un desarrollo que aquí solo se puede esbozar de manera muy incompleta. Mi hipótesis es que la verdad formal, en sentido estricto, sólo puede tener lugar como producto de una abstracción respecto de la verdad trascendental. Esto es así porque la forma lógica del juicio no antecede a la síntesis categorial: al contrario, aunque en el orden temporal Kant encuentra en la tabla de los juicios la clave para el descubrimiento de la tabla de las categorías, la precedencia lógica es inversa. Las categorías no son reflejo de las formas lógicas de los juicios; más bien la forma de los juicios está supeditada a las funciones de enlace designados por las categorías (por ejemplo, la forma lógica de un juicio categórico es la consideración formal de un enlace conforme a la categoría de substancia; la mera forma del sujeto es lo que queda al suprimir las determinaciones sensibles de la categoría de substancia. Cf. KrV A147/B186). De igual modo, cuando el objeto trascendental es considerado con independencia de todo contenido que enlazar, en él no encontramos más que la forma lógica de esos posibles enlaces. Mientras que la correspondenci con tal objeto es la verdad trascendental, la correspondencia con la forma lógica de esos enlaces es la verdad formal. En último término, si bien la lógica formal hace abstracción de los objetos, no puede deslindarse del hecho de que las estructuras judicativas lógico-formales se ordenen respecto a funciones de enlace objetivas, del mismo modo que la lógica trascendental, aunque haga abstracción del contenido intuitivo de los objetos, no puede hacer abstracción del hecho de que sus actos sintéticos se dirigen haci 'alguna' intuición. Por eso es que las formas judicativas ya adelantan algo sobre los modos de síntesis. Así, la mera forma del pensar ya adelanta algo sobre el objeto en sentido propio. De igual modo, la verdad formal 'adelanta' algo de la referencia al objeto, aunque no se refiera a un objeto. Se dice, entonces, que un juicio es formalmente verdadero por analogía, pero sólo en la medida en que esa verdad se ordena a la verdad trascendental, del mismo modo que la verdad trascendental se ordena a la verdad empírica. Esto es así porque la forma lógica del juicio se ordena a la función de unidad ejercida por la categoría.

${ }^{34} \mathrm{Al}$ contrario que el entendimiento divino - explica James Phillips- que es inmediato porque nada se entromete entre él y sus objetos, el conocimiento humano se da siempre a través de los universales. Nuestro entendimiento, para conocer, "debe
} 
preguntas. Justo antes de acometer el giro crítico, en la Dissertatio, Kant explicaba que las representaciones sensibles representaban las cosas como nos aparecen, las intelectuales, como son (MSI 2:392). La concordancia de las representaciones sensibles con las cosas dependía de que éstas fueran causa de aquéllas. Pero, ¿cómo podía concordar la representación intelectual con su objeto, si tiene su origen en la mente? La respuesta en la Crítica es que la objetividad radica precisamente en la unidad que el entendimiento impone. Pero, además, se impone sobre lo sensible. De este modo, no hay ya dos fundamentos distintos de concordancia con el objeto, según la representación sea sensible o intelectual. La concordancia de las facultades con el objeto sólo es posible en la medida en que el objeto es tal por la articulación de ambas facultades. Asimismo, las leyes del entendimiento concuerdan con la experiencia porque ellos son las leyes que rigen sobre la experiencia. La experiencia empírica y los objetos empíricos pueden concordar con nuestras facultades cognoscitivas porque son determinados respecto a su forma por tales facultades. De este modo, la noción de 'verdad trascendental' se presenta como la formulación central de la respuesta a las preguntas en la carta a Herz. Y en efecto, solo unos años después de publicada la Crítica, señalaba, en una de sus lecciones de metafísica, que "se podría decir que la suma de la metafísica se logra al mostrar la posibilidad y el criterio de verdad (Criterium der Wahrheit) de todas las proposiciones sintéticas a priori" (VMet/Mron 29:806). Los conceptos que el entendimiento se forma a priori coinciden con los objetos empíricos en la medida en que todos los objetos son constituidos según el modelo de un objeto trascendental, que es precisamente la expresión de la unidad de los actos del entendimiento a los que las categorías se refieren. La concordancia con este objeto, en la medida en que él a su vez es realizado y restringido (KrV A146/B186, A147/B187) según las condiciones de la intuición, garantiza la verdad de todas las representaciones a priori y, a la vez, posibilita la verdad de todas las representaciones a posteriori. Así es, pues, que la verdad trascendental precede y posibilita a la verdad empírica. La precede en tanto que las condiciones de la objetividad son dadas a priori. Y la posibilita en la medida en que todo conocimiento empírico, para ser conocimiento, ha de regirse según tales condiciones.

En consecuencia, todos nuestros conocimientos empíricos, para ser verdaderamente conocimientos, deben estar en concordancia con las condiciones formales de la experiencia. Por esto, incluso antes de decidir nada sobre su contenido empírico, sabemos ya que han de estar en concordancia con la representación de un objeto en general. En la medida en que se adecuen a éste, podemos afirmar que, independientemente de su contenido empírico, poseen ya verdad trascendental. Pero si la verdad trascendental es condición de toda verdad empírica, entonces la verdad trascendental señala los límites de la verdad empírica, esto es, delimita su territorio: el campo de la experiencia posible (Feld möglicher Erfahrung) ${ }^{35}$. Este es, precisamente, el sentido del famoso pasaje sobre la isla de la verdad:

No solamente hemos recorrido ya la tierra del entendimiento puro, y examinado cuidadosamente cada parte de ella, sino que, además la hemos medido, y hemos determinado su lugar a cada cosa en ella. Pero esta tierra es una isla, y está encerrada por la naturaleza misma en límites inalterables. Es la tierra

paradójicamente dar la espalda a las cosas como son, o, más precisamente (...) debe renunciar a su siempre infundada pretensión de conocimiento inmediato" (Phillips 2008: 585-586).

${ }^{35} \mathrm{KrV}$ A2-3/B7, A95, A227/B280, A248/B304-305, A395, A425/B453, A463/B491, A533/B561, A601/B629, A610/B638, A636/B664, A642/B670, A645/B673, A702/B730. El uso que hace Kant de esta expresión en la Crítica de la razón pura debe entenderse, aunque con cierta cautela, según la exposición que hará más tarde en la Crítica del juicio al respecto de las nociones de Feld, Boden y Gebiet: "Los conceptos, en cuanto se relacionan con objetos, y sin considerar si un conocimiento de los mismos es o no posible, tienen su campo [Feld], que se determina solamente según la relación que su objeto guarda con nuestra facultad de conocer [Erkenntnißvermögen] en general. La parte de ese campo en la cual un conocimiento es posible para nosotros es un territorio [Boden] (territorium) para esos conceptos y para la facultad de conocer requerida para ellos. La parte del territorio donde ellos son legisladores es el dominio [Gebiet] (dictio) de esos conceptos y de las facultades de conocer que les pertenecen" (KU:5:174). En lo que concierne a nuestro tema, dado que se precisa el campo en cuestión como el de la experiencia posible, ha de entenderse, precisamente, como la delimitación del campo (en general) que constituye el territorio de nuestro conocimiento posible. Finalmente, dado que la posibilidad del conocimiento se rige según las categorías, el territorio en que son posibles conocimientos de objetos es el dominio del entendimiento y sus conceptos puros. Así pues, el campo de la experiencia posible, e territorio de nuestro conocimiento objetivo y el dominio del entendimiento son coextensivos. Sin embargo, Kant también utiliza Feld en la Crítica de manera amplia -de acuerdo a la exposición de KU- como el ámbito de los conceptos referidos a objetos cuya posibilidad de conocimiento no está garantizada (p. ej.: KrV A89/B121, B128, B166 nota, A250, B410, A769/B797, A780/B808). Por otra parte, las instancias de "Boden" en KrV suelen designar -también acorde a $\mathrm{KU}$ - un ámbito que ofrece fundamento o base de apoyo al conocimiento (p. ej., KrV A3/B7, A236/B295, A319/B375, A630/B658, A689/B717, A756/784). Las pocas instancias de "Gebiet" (que traducimos como "dominio" y que es vertido por "esfera" en la traducción de García Morente) coinciden plenamente con el uso establecido en $\mathrm{KU}$, si bien se refieren -salvo A255/B310 - al dominio de la razón pura ( $\mathrm{KrV}$ B425, A463/491, A796/824) 
de la verdad (un nombre encantador), rodeada de un océano vasto y tempestuoso, que es el propio asiento de la apariencia ilusoria, en el que mucho banco de niebla, y mucho hielo que pronto se derrite, fingen nuevas tierras, $y$, engañando incesantemente con vacías esperanzas al marino que viaja en busca de descubrimientos, lo complican en aventuras que él jamás puede abandonar, pero que tampoco puede jamás llevar a término. Pero antes de aventurarnos en este mar para explorarlo en todas las latitudes y cerciorarnos de si hay en ellas algo que se pueda esperar, será útil dar previamente una mirada al mapa de la tierra que queremos abandonar, y preguntar, en primer término, si no podríamos contentarnos con lo que ella contiene, o también, si no deberíamos contentarnos [con ello], por necesidad, si acaso no hubiera en parte alguna otro suelo sobre el que pudiéramos establecernos; en segundo término, cuál es el título que nos da la posesión de esta tierra misma, y por el que podemos tenernos por seguros frente a todas las pretensiones enemigas (KrV A236/B295).

En la "Analítica trascendental" - añade Kant acto seguido- se ha respondido de manera suficiente a estas últimas preguntas. Por ello, ya en la introducción a esta disciplina, le había concedido el título de "Lógica de la verdad" (KrV A62/B87). La "Analítica trascendental", en la medida en que ha expuesto las condiciones de posibilidad de toda experiencia posible, y con ello ha marcado sus alcances y límites, es quien ha trazado el mapa con los contornos de la isla de la verdad, a la vez que ha justificado su posesión ${ }^{36}$. Al descubrir los límites del ámbito de la verdad, no sólo se ha establecido el dominio (Gebiet) de la verdad trascendental sino que, en la misma medida, se ha delimitado el territorio (Boden) de la verdad empírica, dado que, cualquier conocimiento, para poder ser verdadero empíricamente, ha de cumplir ya las exigencias de la verdad trascendental ${ }^{37}$.

Precisamente en este sentido Kant describe, en la "Doctrina del método", la tarea crítica como una cartografía de la verdad. Si me represento la superficie de la Tierra como un plato, no puedo saber hasta dónde se extiende. Al avanzar en ella se aleja siempre el horizonte, con lo que se me hace patente que siempre podría avanzar más y, por tanto, que mi conocimiento de la Tierra, en cada ocasión, tiene limitaciones (Schranken). Pero no por eso conozco los límites (Grenzen) ${ }^{38}$ de toda descripción posible de la Tierra. Al descubrirse que la Tierra es una esfera, es posible determinar $a$ priori su diámetro, a partir de una pequeña porción de ella. Así, aún sin conocer propiamente nada sobre los objetos en la Tierra, conozco su extensión y sus límites (KrV A759/B787). Análogamente dice Kant- la razón humana:

no es algo semejante a una llanura extendida en lejanías indeterminables, cuyos límites se conocieran sólo en general; sino que debe compararse más bien con una esfera, cuyo radio se puede calcular a partir de la curvatura del arco sobre la superficie de ella (a partir de la naturaleza de las proposiciones sintéticas a priori), y a partir del cual luego se puede obtener con seguridad también el contenido y la delimitación de ella. Fuera de esta esfera (campo de la experiencia) nada es objeto para ella; y hasta las preguntas acerca de tales presuntos objetos atañen sólo a principios subjetivos de una determinación completa de las relaciones que pueden presentarse entre los conceptos del entendimiento dentro de esa esfera (KrV A762/B790).

\footnotetext{
${ }^{36}$ Con esta metáfora de la justificación del título de la posesión Kant alude a la función de la "Deducción trascendental", presentada, precisamente, bajo esta terminología jurídica ( $\mathrm{KrV}$ A84/B116), y con la que caracterizaba, ya desde Träume, a la metafísica: "un pequeño país tiene siempre muchas fronteras y, en general, también le importa más conocer y asegurar sus posesiones (...), esta ventaja [de la metafísica] es la más desconocida y, a la vez, la más importante” (TG 2:368).

${ }^{37}$ Aunque Kant define Gebiet y Boden en función de conceptos, y por tanto podría decirse que son los conceptos los que tienen dominio y territorio (cf. KU 5:174), me parece legítimo usar estos términos respecto a los sentidos de verdad. Si bien la verdad trascendental no legisla sobre el conocimiento empírico del modo en que lo hacen los conceptos puros, es la relación con un objeto en general lo que delimita el ámbito del conocimiento posible y, en este sentido, la verdad trascendental ejerce un papel rector en el trazado de los límites del conocimiento. La verdad empírica, de manera análoga a los conceptos empíricos, tiene suelo o territorio (Boden) entre tales límites, pero dado que no tiene función legislativa, sólo tiene residencia (Aufenthalt/domicilium) (cf. KU 5:174). A la verdad formal, por su parte, correspondería al campo (Feld) de lo inteligible, esto es, de todo lo que se pueda pensar.

${ }^{38}$ Las limitaciones (Schranken) son entendidas por Kant como 'meras negaciones', como el "conocimiento indeterminado de una ignorancia que no puede suprimirse por completo", en tanto que indican que el conocimiento carece de totalidad absoluta Mediante la constatación de que siempre nos queda algo por saber, puede conocerse a posteriori la limitación de la razón. Pero esto no indica nada acerca de la necesidad o contingencia de la ignorancia en cuestión. Los límites (Grenzen), en cambio, son determinaciones restrictivas, que señalan la ignorancia invencible respecto a todas las posibles cuestiones de cierta especie. El escepticismo podría describirse como una filosofía de las limitaciones, dado que constata continuamente las limitaciones de la razón. Pero, en la medida en que no asigna límites, deviene en desconfianza respecto a esta última, pues no produce conocimiento respecto a la ignorancia inevitable. La tarea crítica es propiamente la investigación de los límites y, en tanto que da lugar a cierto conocimiento -conocimiento de los límites según fundamentos a priori-, es ciencia (cf. KrV A758-769/B786-797; Prol 4:350$357)$.
} 
De este modo, aún sin detenernos en el examen de los objetos contenidos en esta esfera ${ }^{39}$, podemos conocer ya un límite respecto a estos objetos, y determinar a priori que todo "presunto objeto" fuera de tal esfera - es decir, que no cumpla las exigencias formales de la verdad trascendental- no puede dar lugar a conocimientos verdaderos. Todo conocimiento empírico verdadero ha de ser, pues, trascendentalmente verdadero. Pero de esto no se sigue que todo conocimiento verdadero trascendentalmente ha de ser empíricamente verdadero.

La verdad trascendental precede y posibilita la verdad empírica, pero no la determina. En tanto que establece la objetividad del conocimiento, lo que la verdad trascendental posibilita es la relación del conocimiento empírico con un objeto. Pero, dado que no tiene en cuenta el contenido empírico particular de cada conocimiento, no puede decidir nada aún sobre su verdad empírica. De este modo, la verdad trascendental precede y posibilita a la verdad empírica, pero en la misma medida hace posible también la falsedad empírica, entendida como la inadecuación del contenido empírico específico respecto al objeto al que se refiere. La falsedad empírica requiere, pues, también de realidad objetiva y, en este sentido, Kant señala que "un conocimiento es falso cuando no concuerda con el objeto al que se refiere, aunque contenga algo que quizá pueda valer para otros objetos" ( $\mathrm{KrV}$ A58/B83). Así pues, la verdad trascendental es una condición necesaria para que se le pueda asignar un valor de verdad a todo pretendido conocimiento empírico ${ }^{40}$.

Según lo dicho en las secciones anteriores, no todo conocimiento trascendentalmente verdadero es también verdadero empíricamente. Pero, ¿qué sucede con los pretendidos conocimientos que no cumplen las condiciones de verdad trascendental? En la metáfora sobre la isla de la verdad, Kant describe a todo lo que rodea tal territorio con el nombre del 'océano tempestuoso de la ilusión'. Precisamente, los presuntos conocimientos que han quedado fuera de estos límites son las ilusiones trascendentales, a las que Kant dedica la "Dialéctica trascendental", a la que llama, con justicia "lógica de la ilusión" (KrV A131/B170). Así pues, Kant llama ilusión trascendental (transscendentalen Schein) a las pretensiones de conocimiento que se dirigen más allá del campo de la experiencia posible, es decir, que sobrepasan los contornos delineados por la verdad trascendental, creando el espejismo de un ensanchamiento del entendimiento puro (cf. KrV A293-295/B349-352).

Kant atribuye el origen de las ilusiones trascendentales al uso objetivo de los principios meramente subjetivos de la razón humana, con lo cual se hace una hipóstasis de las ideas de la razón

${ }^{39}$ Puede conducir a equívocos la traducción generalizada de Gebiet por 'esfera'. Gebiet (dominio) es tomado del lenguaje jurídico y se refiere al papel legislativo de una facultad sobre sus objetos. En cambio, esfera (Sphäre/Kügel) es tomada en estos pasajes según las analogías geográficas de Kant y corresponde -como Kant indica- al campo (Feld) de la experiencia, esto es, al territorio (Boden) de nuestro conocimiento empírico.

${ }^{40}$ Con esto pretendo matizar la tesis, famosamente defendida por Prauss, de que todo conocimiento - no sólo el empírico- necesita de verdad trascendental para tener un valor de verdad. Prauss entiende que el objeto de la lógica trascendental no es la verdad (Wahrheit) como opuesta a la falsedad, sino la Wahrheitsdifferenz, esto es la 'no-indiferencia' respecto a la verdad; en otras palabras, la posibilidad de asignar un valor de verdad (verdadero o falso) a un conocimiento; e identifica la validez objetiva como la condición que permite asignar tal valor de verdad al conocimiento. Según esto, aquellos supuestos conocimientos que no tienen validez objetiva (verdad trascendental) no son falsos, pues no tienen un valor de verdad: son ilusiones trascendentales (Praus 1971: 86 ss, 1969: 180-182). También señala que la verdad trascendental tiene dos significados para Kant: Wahrheitsdifferenz para los juicios empíricos, y verdad a priori para los principios del entendimiento (ibídem 68 nota 181). Esto último, sin embargo, es necesario matizarlo, pues para Kant 'verdad trascendental' significa exactamente lo mismo para ambos tipos de juicios: concordancia con la representación de un objeto en general. Pero es cierto que este sentido de verdad es propiamente el valor de verdad para el conocimiento sintético a priori, y posibilita la verdad empírica del a posteriori, como hemos visto hasta ahora. Por otra, parte, me parece un punto débil el que Prauss distinga sólo entre Wahrheitsdifferenz-ilusión y verdad-falsedad. Según esto, lo que contradice a la lógica formal sería falso en el mismo sentido en que es falso el error empírico (ibídem 181). Stuhlmann-Laeisz, también en esta línea, señala que si Prauss tuviese razón, todos los juicos contradictorios serían trascendentalmente verdaderos: la verdad trascendental sería una condición necesaria para la contradicción. Pero Kant sostiene que la no contradicción es conditio sine qua non de toda verdad (Stuhlmann-Laeisz 1976: 51n). Por otra parte, Stuhlmann-Laeisz también señala, correctamente, que hay juicios que carecen de verdad trascendental y que, sin embargo, tienen valor de verdad. Por ejemplo, Kant dice que "el mundo es finito" y "el mundo es infinito" son falsas (ibídem 30). En todo caso, Stuhlmann-Laeisz desarrolla una interpretación distinta a la de Prauss pero de corte similar, distinguiendo entre juicios adecuados (verträglich) e inadecuados (unverträglich), según tengan o no validez objetiva. Los juicios empíricos son adecuados en la medida en tanto tienen verdad trascendental, aun cuando puedan ser verdaderos o falsos. Los juicios con pretensiones trascendentes serían inadecuados, pues no tienen referencia a objeto alguno (verdad trascendental), y en esa medida serían también falsos (ibídem $28 \mathrm{ss}$ ). Más recientemente, Vanzo ha argumentado también en contra de la lectura según la cual Kant concede valor de verdad sólo a los juicios con validez objetiva, mostrando, por una parte, evidencia textual de que Kant concede de hecho valor de verdad a juicios sin validez objetivo y, por otra parte, mostrando que aquella lectura es incongruente con el propósito kantiano de restringir el campo del conocimiento en favor de la fe (Vanzo 2012 114-118). Coincido con Stuhlmann-Laeisz y con Vanzo en que Kant no identifica validez objetiva y posibilidad de tener valor de verdad. Pero contra Stuhlmann-Laeisz, y de acuerdo con Vanzo, me parece incorrecto sostener que la falta de validez objetiva implique para Kant, ipso facto, la falsedad de un conocimiento. 
(alma, mundo y Dios), y se les concede, de forma igualmente ilusoria, realidad objetiva a sus correspondientes raciocinios (paralogismo, antinomia e ideal). Sin embargo, la ilusión trascendental no yace realmente en las ideas de la razón, sino en su uso trascendente, cuando habría de ser inmanente. Tales ideas se ordenan a los intereses de la razón cuando son usados heurísticamente para la sistematización del conocimiento (KrV A663/B691, A666/B694; cf. Llano 2002: 111-119, Flamarique 1993: 16-19). Ahora bien, también podemos considerar dentro del ámbito de la ilusión trascendental (como opuestas a la verdad trascendental) la objetivación de aquellos conceptos que sin ser productos de la natural tendencia de la razón a lo incondicionado- transgreden los límites de la experiencia (e.g. los conceptos de 'sustancia inmaterial' o de 'clarividencia' $)^{41}$.

La pregunta relevante es, ¿qué valor de verdad se les puede conceder a los juicios que incurren en este tipo error? Dado que no cumplen con las condiciones de verdad trascendental no pueden ser, desde luego, verdaderos empíricamente. Sin embargo, su falta de acuerdo con el objeto no es aquella que se da en la falsedad empírica: mientras que esta última apunta a un objeto -aunque da cuenta incorrecta de su contenido empírico- la falta de verdad trascendental significa que estos presuntos conocimientos no concuerdan con las condiciones generales de la objetividad y, por tanto, no apuntan a nada que pueda ser un objeto para nosotros ${ }^{42}$. Una aparente solución sería sostener que, dado que carecen de objeto, no hay un criterio para establecer si concuerdan o no con su objeto y, por ello, carecen de valor alguno de verdad (Prauss 1969: 180-181; Hanna 2000: 230; Höffe 2010: 59; Paek 2005: 157-158; Svendsen 2001: 848-849). Otra alternativa es dar a todos estos juicios por falsos, dado que, precisamente, no pueden concordar con su objeto, por no tener objeto (cf. StuhlmannLaeisz 1976: 28-30; Mohanty 1999: 208).

Es difícil atribuirle a Kant la opinión descrita en la primera alternativa, puesto que éste, de hecho, concede expresamente valor de verdad a juicios sin verdad trascendental. Por ejemplo, sostiene que todos los juicios analíticos que no incurren en contradicción son verdaderos; y afirma que las antinomias sobre la limitación del mundo que son ambas falsas (KrV A502-507/B530-535, cf. Vanzo 2012: 115, 2005: 505-531). La segunda alternativa, aunque a primera vista podría parecer más plausible -después de todo, nos enfrentamos a lo que Kant llama 'ilusiones' trascendentales-, se enfrenta con el mismo problema que la primera: los juicios analíticos son verdaderos. Pero hay aún más. Las ideas de un Ser Supremo y del alma no pueden ser refutadas, así que no podemos, en primera instancia, decir que son falsas: los mismos fundamentos por los que se niega a la razón la capacidad de afirmarlos, demuestran la imposibilidad de negarlos (KrV A640-641/B668-669; cf. KrV A672-674/B6700-702, A696-697/B6724-725, KU 5:400). Incluso, estas ideas son retomadas por la razón práctica como artículos de fe (existencia de Dios e inmortalidad del alma), y si bien aún ahí tampoco cabe conocimiento de ellas, son objeto de 'certeza moral' (KrV A828-829/B856-857). Y más aún, el concepto de libertad -carente de suelo (Boden) para la razón teórica pura- adquiere, sin embargo, realidad objetiva en el dominio de la razón práctica ( $\mathrm{KrV}$ A802/B803, $\mathrm{KpV} 5: 47$, cf. $\mathrm{KrV}$ Bxxvi nota). Decir que estos presuntos conocimientos son 'ilusiones' no equivale tanto a afirmar su falsedad, sino a mostrar que dan la apariencia de conocimiento objetivo, cuando, en realidad, no conocen -en el sentido estricto de la palabra- nada. Pero esto último no sólo implica la imposibilidad de conocimiento positivo sobre estos 'objetos', sino que también nos advierte sobre la imposibilidad de negarlos absolutamente. Este movimiento es tan ilegítimo como su contrario: sostener la imposibilidad o inexistencia absoluta de estos conceptos por caer fuera del dominio de muestro entendimiento significaría querer hacer de los principios de la posibilidad de la experiencia condiciones generales de las cosas en sí mismas, esto es, principios trascendentes (cf. Prol 4:351).

\footnotetext{
${ }^{41}$ Kant atribuye a la "Dialéctica trascendental" la tarea de descubrir la ilusión de los principios 'trascendentes' (transscendente Gründsätze), es decir, de aquellos principios que pretenden sobrepasar los límites de la experiencia posible, en contraste con los inmanentes (immnente Gründsätze), cuya aplicación se contiene dentro de tales límites. Si bien Kant distingue entre estos principios trascendentes y el uso -0 abuso (mißbrauch)- trascendental (transscendental) de las categorías, ambos constituyen propiamente una transgresión a los límites y devienen igualmente en ilusiones trascendentales. Sin embargo, mientras que el uso trascendental de las categorías puede tomarse como un error puntual, los principios trascendentes, en cambio, incitan sistemáticamente a la eliminación de los límites. Por ello ellos son el objeto propio de la "Dialéctica Trascendental".

${ }^{42}$ Es necesario aclarar, sin embargo, que este tipo de conceptos podrían ser sujetos de juicios verdaderos, siempre y cuando estos juicios sean analíticos: "Dios es omnipotente", "La clarividencia consiste en la facultad de intuir el futuro" son juicios analítico verdaderos (cf. Vanzo 2012: 116). El problema en cuestión surge, en primer lugar, cuando se ponen como sujetos de juicios sintéticos (e.g. "Dios existe”), que son, precisamente, los que ‘extienden' el conocimiento.
} 
Esta última consideración es, a mi parecer, la razón sistemática más importante por la cual no cabe adjudicarle a Kant la posición de que la carencia de verdad trascendental indica la falsedad del juicio. Pero tampoco ha de significar, necesariamente, que tales juicios carecen de valor de verdad. De hecho, como hemos visto, hay juicios que carecen de verdad trascendental de los que podemos afirmar su verdad (juicios analíticos) ${ }^{43}$, de otros podemos afirmar su falsedad (la negación de los principios del entendimiento puro, las antinomias sobre la limitación o ilimitación del mundo en el espacio y tiempo), y de otros, sencillamente no podemos decidirnos, no porque, en sí mismos, no les corresponda valor alguno, sino porque, precisamente, lo que son en sí mismos no es nada para nosotros: las condiciones que determinarían su verdad o falsedad trascienden nuestro conocimiento posible (KrV A750-751/B778-779).

\section{Conclusiones}

Que Kant no exponga sistemáticamente una doctrina de la verdad puede tomarse como una señal de que el filósofo no pretendió en ningún momento redefinir este concepto. La noción de 'verdad trascendental', tal como aparece en la doctrina kantiana, es muestra de ello. Aunque revela una profunda novedad en la manera de entender el acuerdo del conocimiento con su objeto, descansa en la definición nominal heredada de la tradición ${ }^{44}$. Así, aunque la noción kantiana de 'verdad trascendental' supone una reinterpretación de la verdad, no es, en modo alguno, una redefinición. Al contrario: en ella está supuesta la concordancia con el objeto.

La verdad trascendental constituye para Kant -en consonancia con planteamientos filosóficos anteriores- la posibilidad misma de los objetos y fundamenta la relación de éstos con nuestro conocimiento. Pero su interpretación no recurre -como sucedía en la escolástica y en el racionalismo, respectivamente- a la verdad ontológica (concordancia con el entendimiento divino) ni a la unidad, orden y completitud de las determinaciones internas de las cosas para dar cuenta de su posibilidad interna y de la posibilidad de nuestro conocimiento de ellas. La verdad trascendental, como la entiende Kant, está desligada de las condiciones de posibilidad de las cosas mismas, y se refiere únicamente a las condiciones de posibilidad de nuestro conocimiento de ellas. Esto es: se refiere a la forma de la experiencia en general o, lo que es lo mismo, desde otra perspectiva, a las condiciones por las que un objeto es, precisamente, objeto para nosotros. De este modo, ser objeto es tener verdad trascendental.

Entender la verdad trascendental como la concordancia con las condiciones a priori de la objetividad (en otras palabras, la concordancia con un objeto trascendental) permite dar cuenta de la posibilidad de establecer la verdad del conocimiento a priori. Las categorías, los principios del entendimiento puro, e incluso las formas puras del espacio y el tiempo son verdaderos porque, aun antes de toda experiencia, guardan conformidad con la representación de un objeto en general. Pero esto es así porque todas aquellas categorías, principios y formas son, a la vez, las condiciones de este objeto, en la medida en que son las condiciones de toda experiencia posible. De este modo, estas condiciones son, a la vez, las condiciones suficientes y necesarias de la verdad trascendental. Al ser condiciones a priori, y al no referirse a una multiplicidad de objetos, sino a las condiciones de objetividad, que son siempre únicas y las mismas, la lógica trascendental permite ofrecer criterios universales y suficientes de verdad trascendental. Estos mismos criterios son, a la vez, los criterios de posibilidad de los objetos; lo que permite entender también cómo todos los objetos de experiencia son ya trascendentalmente verdaderos, y cómo todos los juicios sobre ellos, aun cuando fueran erróneos, contienen ya también un grado de verdad. Así pues, la verdad trascendental posibilita la experiencia empírica y, en esa misma medida, precede y posibilita a la verdad empírica. Pero esto significa, a la vez, que limita el territorio de esa verdad. Nada que no sea trascendentalmente verdadero puede ser empíricamente verdadero, pero tampoco puede darse por empíricamente falso. Los pretendidos conocimientos que carecen de verdad trascendental, en tanto que tratan de objetos que nunca pueden

\footnotetext{
${ }^{43}$ Pero esta verdad sólo satisface un nivel lógico de objetividad. Tampoco es verdad en el mismo sentido que lo es el conocimiento empírico.

${ }^{44}$ Schulz dedica buena parte del cuarto capítulo de su estudio sobre la verdad en Santo Tomás y en Kant precisamente a mostrar la continuidad entre la postura kantiana y la tradición escolástica y clásica respecto a la verdad. Si bien esta autora deja de lado aspectos esenciales de la doctrina kantiana que habrían de matizar sus conclusiones (por ejemplo, la restricción del territorio de la verdad o el papel del objeto trascendental como punto de referencia de toda verdad), logra mostrar, con tino, que la noción kantiana de verdad tiene, en muchos aspectos, más en común con la doctrina clásica de la correspondencia que con teorías de la coherencia -contra Prauss, Kemp Smith o Rescher (Schulz 1993: 153 ss)-.
} 
ser objetos para nosotros, quedan siempre velados tras el mar borrascoso que nos impide saber si, acaso, algún objeto les puede corresponder.

\section{Bibliografía}

ALBRECHT, Michael: "Wahrheitsbegriffe von Descartes bis Kant" en ENDERS, M. y SZAIF, J (eds.): Die Geschichte des philosophischen Begriffs der Wahrheit, Berlín, De Gruyter, 2006.

ARIAS ALBISU, Martín: "Acerca del carácter ontológico del esquematismo trascendental", Contrastes. Revista Internacional de Filosofía 17 (2012) 7-25.

BAUMGARTEN, Alexandri Gottlieb: Metaphysica, Halle-Magdeburgo, Karl Hermann Hemmerde, 1757 ( $4^{\mathrm{a}}$ ed). Reproducido en: KANT, I: Kant's gesammelte Schriften, Preussischen Akademie der Wissenschaften, Berlin, 1900-, Vol. 17.

BEADE, Ileana P: "Consideraciones acerca del concepto kantiano de objeto trascendental”, Tópicos 36 (2009) 83-118.

CABRERA, Isabel: "Conocimiento necesario en Kant”, Diánoia 41 (1995) 125-43.

CAPOZZI, Mirella: Kant e la lógica, Napoli, Bibliopolis, 2002.

CICOVACKI, Predrag: Between Truth and Ilussion: Kant at the Crossroads of Modernity, Oxford, Rowman \& Littlefield Publishers, Inc., 2002.

CICOVACKI, Predrag: "Kant on the Nature of Truth," en ROBINSON H. (ed.): Proceedings of the Eight International Kant Congress, Milwaukee, Marquette University Press, 1995, Vol II.

ESTERHUYSE, W. P.: "From Plato to Kant: The Problem of Truth" En BECK, L. W. (ed.): Proceedings of the Third International Kant Congress, Dordrecht-Holland, D. Reidel Publishing Company, 1972.

FLAMARIQUE, Lourdes: Dos momentos de la metafísica en el criticismo kantiano, Pamplona, Cuadernos de Anuario Filosófico, 1993.

FLAMARIQUE, Lourdes: Necesidad y conocimiento. Fundamentos de la teoría crítica de I. Kant, Pamplona, EUNSA, 1991.

GUTIÉRREZ, Carlos B: "La noción de experiencia en Kant”, Ideas y Valores 34 (1985) 5-20.

HANNA, Robert: "Kant, Truth and Human Nature", British Journal for the History of Philosophy 8 (2000) 225-50.

HEIDEGGER, Martin: Sein und Zeit. Tübingen, Niemeyer, 1979.

HILTSCHER, Reinhard: Wahrheit und Reflexion. Eine transzendentalphilosophische Studie zum Wahrheitsbegriff bei Kant, dem frühen Fichte und Hegel, Bonn, Bouvier Verlag, 1988.

HÖFFE, Otfried: Kant's Critique of Pure Reason. The Foundation of Modern Philosophy, DordrechtLondon, Springer, 2010.

HOFMEISTER, Heimo E.M: "The Problem of Truth in the 'Critique of Pure Reason'”, en BECK, L. W. (ed.): Proceedings of the Third International Kant Congress, Dordrecht-Holland, D. Reidel Publishing Company, 1972.

HOWELL, Robert: Kant's Transcendental Deduction. An Analysis of Main Themes in His Critical Philosophy, Dordrecht, Kluwer Academic Publishers, 1992.

KANT, Immanuel: Gesammelte Schriften, Berlin-Leipzig, Preussische Akademie der Wissenschaften, Deutsche Akademie der Wissenschaften zu Berlin, Akademie der Wissenschaften zu Göttingen, Georg Reimer, Walter de Gruyter \& Co, 1900-. Los textos citados en castellano provienen de las traducciones realizadas por Mario Caimi: Crítica de la razón pura, México, Fondo de cultura económica, 2009 y por Manuel García Morente: Crítica del juicio, Traducido por. Madrid, Tecnos, 2007.

LLANO, Alejandro: Fenómeno y trascendencia en Kant, Pamplona, EUNSA, 2002.

MEIER, Georg Friedrich: Metaphysik, Halle, Johann Justinus Gebauer, 1765 (2 $2^{\mathrm{a}}$ ed.). Facsímil en: Metaphysik, Hildesheim, Olms, 2007. 
MOHANTY, J. N.: "Kant on 'Truth'”, en Logic, Truth and the Modalities. From a Phenomenological Perspective, Dordrecht, Kluwer Academic Publishers, 1999.

NEIMAN, Susan, The Unity of Reason. Rereading Kant, Oxford, Oxford University Press, 1994.

NENON, Thomas J.: Objektivität und endliche Erkenntnis. Kants transzendentalphilosophische Korrespondenztheorie der Wahrheit, Freiburg, Alber, 1986.

PAEK, Chong-Hyon: "Kant's Theory of Transcendental Truth as Ontology”, Kant-Studien 96 (2005) $147-60$.

PALACIOS, Juan Miguel: El idealismo trascendental: Teoría de la verdad, Madrid, Avarigani Editores, 2013 (2a ed.).

PHILLIPS, James: "Truth, Knowledge and the Thing in Itself", en ROHDEN, V et al (eds.): Recht Und Frieden in Der Philosophie Kants: Akten Des X. Internationalen Kant-Kongresses, Berlin, Walter de Gruyter, 2008.

PIEPER, Josef: "La verdad de las cosas. Una investigación sobre la antropología de la alta edad media," en El descubrimiento de la realidad, Madrid, Ediciones Rialp, 1974.

PRAUSS, Gerold: Erscheinung bei Kant. Ein Problem der "Kritik der reinen Vernunft", Berlin, Walter de Gruyter \& Co., 1971.

PRAUSS, Gerold: “Zum Wahrheitsproblem bei Kant” Kant-Studien 60 (1969) 166-82.

ROSALES, Alberto: Sein und Subjektivität bei Kant. Zum subjektiven Ursprung der Kategorien, Berlin, Walter de Gruyter, 2000.

ROSENKOETTER, Timothy: "Truth Criteria and the Very Project of a Transcendental Logic", Archiv Für Geschichte Der Philosophie 91 (2009) 193-236.

SCHULZ, Gudrun: Veritas est adaequatio intellectus et rei. Untersuchungen zur Wahrheitslehre des Thomas von Aquin und zur Kritik Kants an einem überlieferten Wahrheitsbegriff, Leiden, E.J. Brill, 1993.

SGARBI, Marco: "The Historical Genesis of the Kantian Concept of Transcendental”, Archiv Für Begriffsgeschichte 53 (2011) 97-117.

STUHLMANN-LAEISZ, Rainer: Kants Logik. Eine Interpretation Auf Der Grundlage von Vorlesungen, Veröffentlichen Werken Und Nachlass, Berlin, Walter de Gruyter, 1976.

SVENDSEN, Lars: "Kant's Theory of Empirical Truth", en GERHARDT, V. et al (eds.) Kant Und Die Berliner Aufklärung. Akten Des IX. Internationalen Kant-Kongresses, Berlin, Walter de Gruyter, 2001.

UNDERWOOD, Lori J.: Kant's Correspondence Theory of Truth, New York, Peter Lang Publishing Inc, 2003.

VANZO, Alberto: "Kant on the Nominal Definition of Truth", Kant-Studien 101 (2010) 147-66.

VANZO, Alberto: "Kant on Truth-Aptness", History and Philosophy of Logic 33 (2012) 109-26.

VANZO, Alberto: "Kant's Treatment of the Mathematical Antinomies in the First Critique and in the Prolegomena: A Comparison", Croatian Journal of Philosophy, no. 15 (2005) 505-31.

VÁZQUEZ LOBEIRAS, María Jesús: Die Logik und ihr Spiegelbild. Das Verhältnis von formaler und transzendentaler Logik in Kants philosophischer Entwicklung, Frankfurt am Main, Peter Lang, 1998.

WAGNER, Hans: "Zu Kants Auffassung bezüglich des Verhältnisses zwischen Formal- und Transzendentallogik. Kritik der reinen Vernunft A 57-64/B 82-88”, Kant-Studien 68 (1977) 71-76.

WALKER, Ralph C.S.: "Empirical Realism and Transcendental Anti-Realism II", Proceedings of the Aristotelian Society, Supplementary Volumes 57 (1983) 155-77.

WOLFF, Christian: Philosophia prima sive ontologia, Frankfurt-Leipzig, Officina Libraria Rengeriana, 1736 (9a ed.). Facsímil en: ÉCOLE, J. (ed.): WOLFF, Gesammelte Werke, Hildesheim, Olms, 1962, Vol II, 3. 